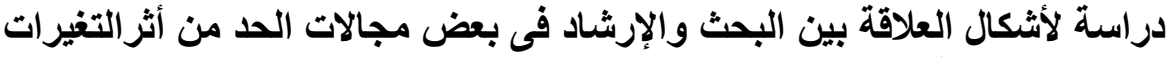

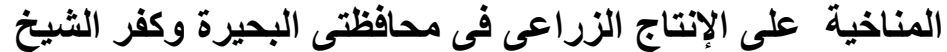

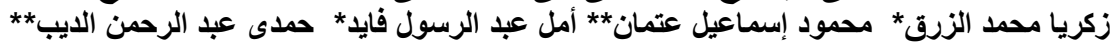 *كلية الزراعة بلدمنهور
}

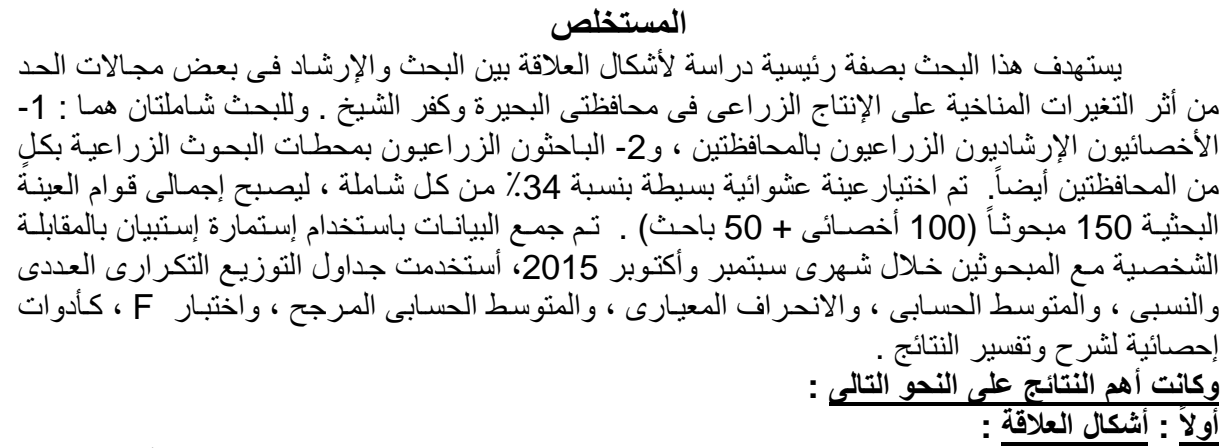
« 68 \% ، و 26.7\% ، و62\% من المبحوثين كان تقدير هم لارجة التعاون بين البحث و الإرشاد أنها متوسطة

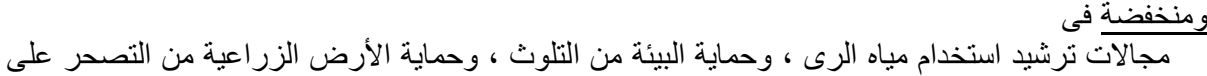

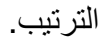
« 61.3\% ، و70\% ، و73.4\% من المبحوثين كان تقدير هم لارجة التنسيق بين البحث و الإرشاد أنها متوسطة

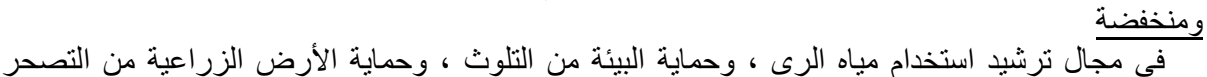

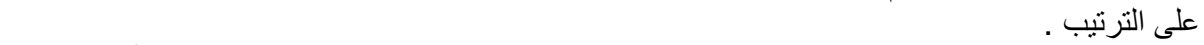

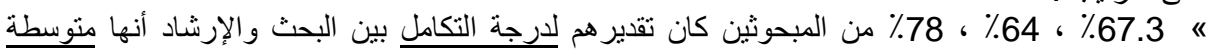

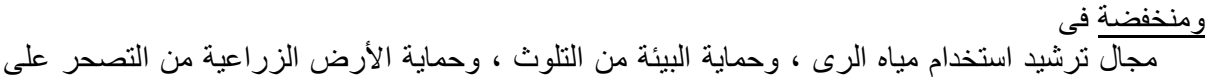
الترتيب . « 89.3\% ، و80.6\% ، و87.3\% من المبحوثين كان تقديرهم للدرجة الصراع بين البحث والإرشاد أنها

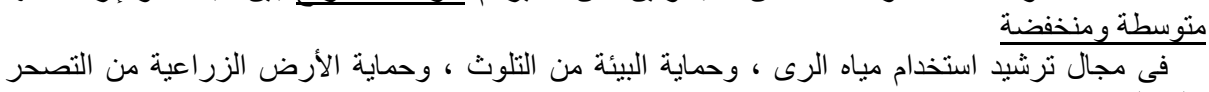

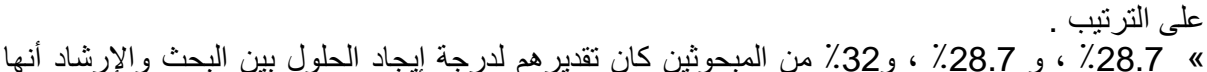

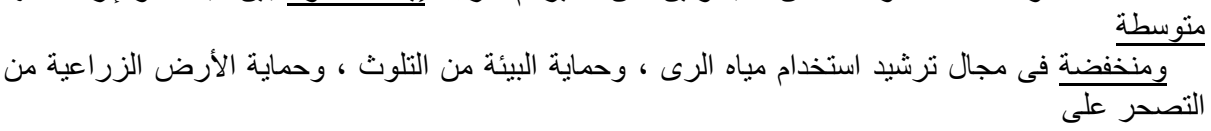

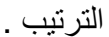
ثانياً : طبيعة العلاقة :

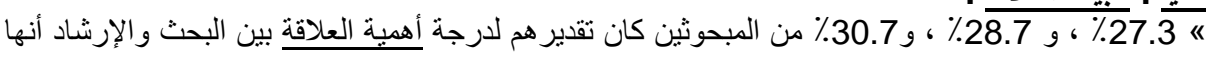

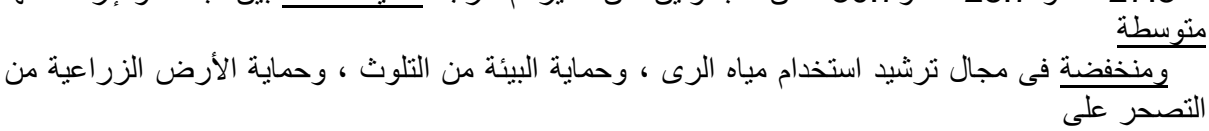
الترتيب . « 52٪ ، و 5.4 57.4 ، و 56.7٪ من المبحوثين كان تقدير هم لدرجة رسمية العلاقة بين البحث و الإرشاد أنها

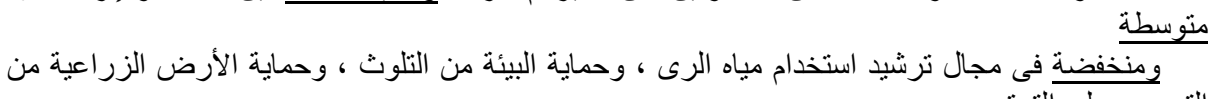


« 62٪ ، و66\% ، و 70٪ من المبحوثين كان تقدير هم لدرجة تكرار العلاقة بين البحث والإرشاد أنها متوسطة

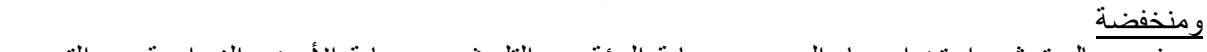
فلى مجال ترشيد استخدام مياه الرى ، وحماية البيئة من التلوث ، وحماية الأرض الزراعية من التصحر

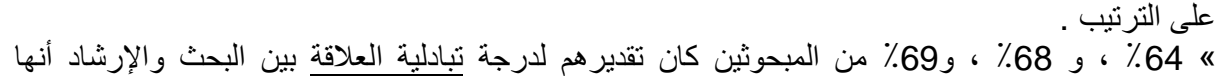

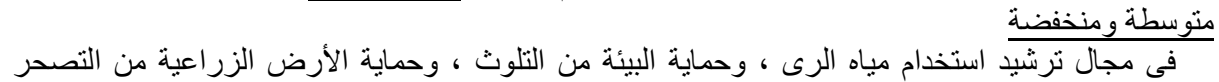

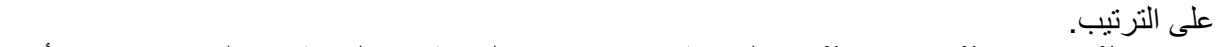
« ع5.3\% ، ، و33.3\% ، و55.4\% من المبحوثين كان تقدير هم لدرجة قوة العلاقة بين البحث والإرشاد أنها

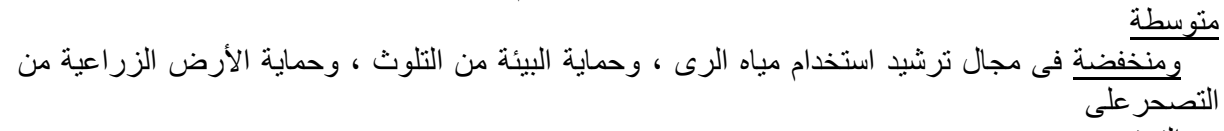
الترتيب . ثالثاً : قوة التفاعل الإتصالي:

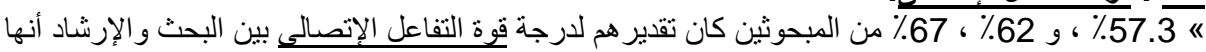

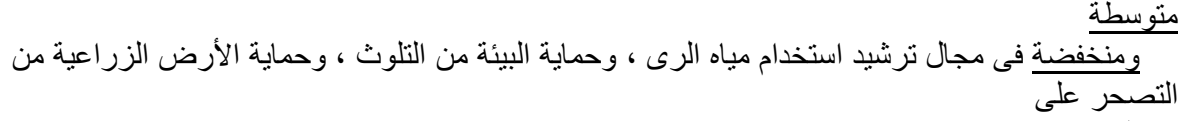
الترتيب . التبك

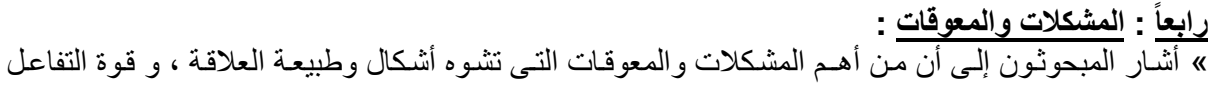
البحث والإرشاد فى المجالات المدروسة من وجهة نظرهم ، هى: عدم تو افر الموارد المالية الكافية ، و عدم الإتصالى بين الإن البين

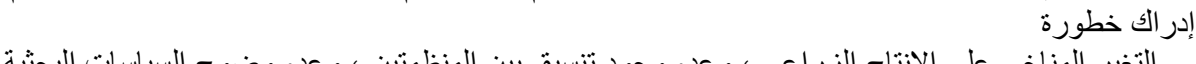
التغير المناخى على الإنتاج الزراعى ، و عدم وجود تتسيق بين المنظمتين ، و عدم وضوح السياسات البحثية والإرشادية ، و وغياب الحافز المادى للباحثين والأخصائيين

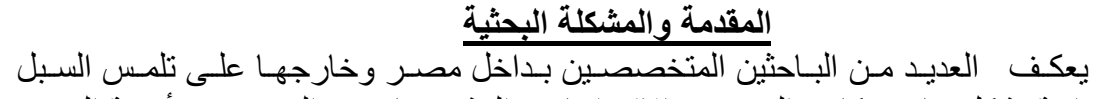

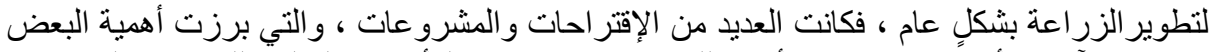

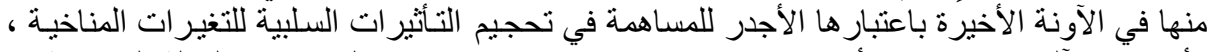
و أهم هذه الآليات كما ذكر ها أبو حديد (2010، صألة :

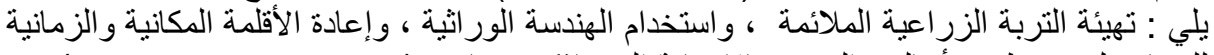

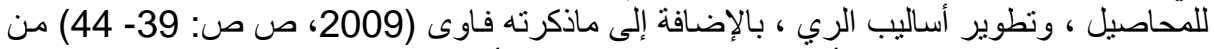

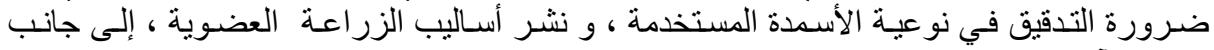

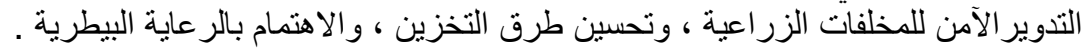

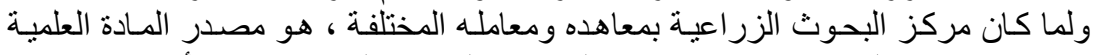

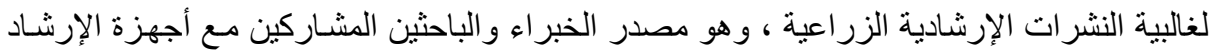

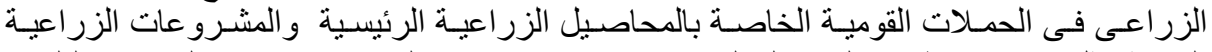

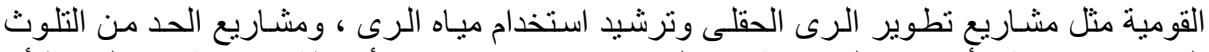

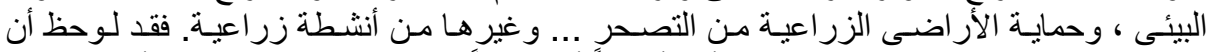

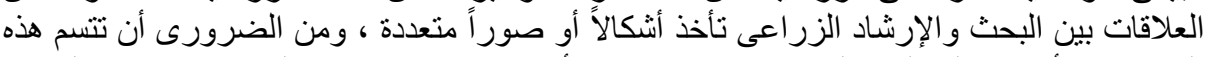

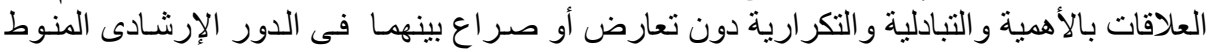

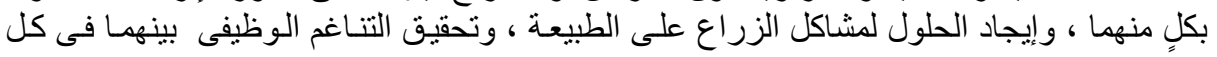


العمليات الإدارية والتظظيمية التى يشتركان فيها ولها علاقة بالحد من المخاطر المحتملة على الإنتاج

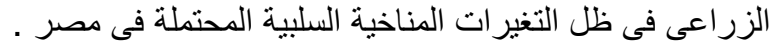

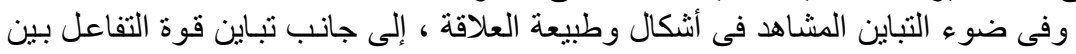

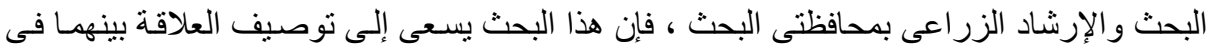

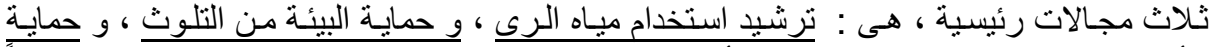

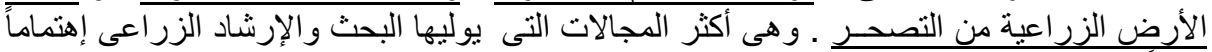

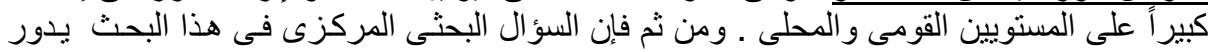

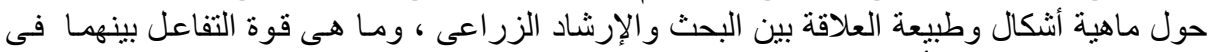

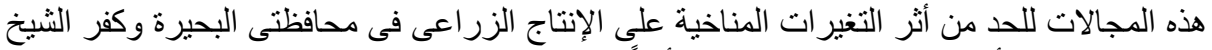
، باعتبار هما من أكثر المحافظات المصرية نأثراً بالتغير الات التناج الزناخية فى الحاضر و المستقبل .

\section{أهــــاف البحث}

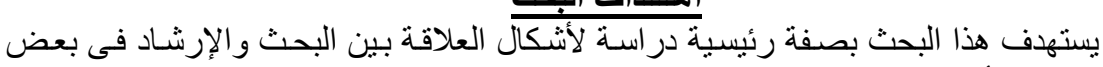

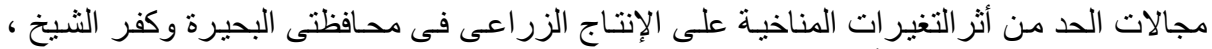

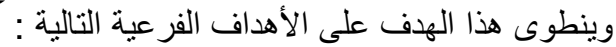

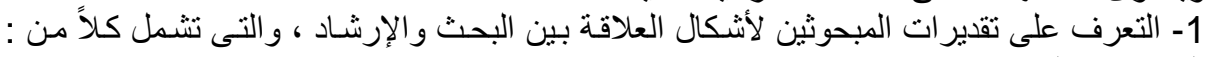

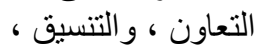
و التكامل ، و الصر العن ، ، وإيجاد الحلول ، وذلك فى مجالات ترشيد استخدام مياه الرى ، وحمايـة

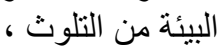

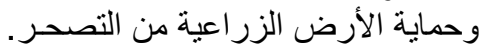

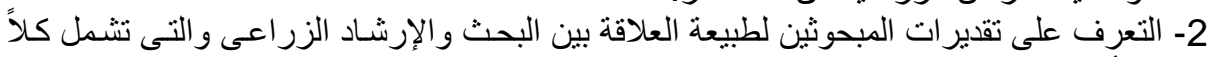

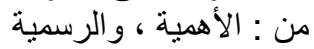
، و التكر ارية ، و التبادلية ، و القوة ، وذلك فى مجالات ترشيد استخدام ميـاه الرى ، وحمايـة البيئة

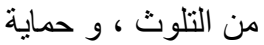

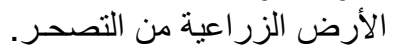

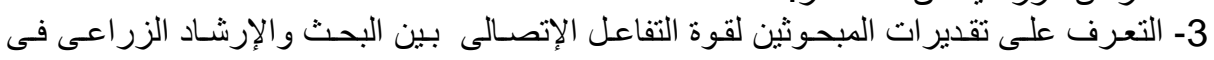
مجالات ترشيد استخدام مياه

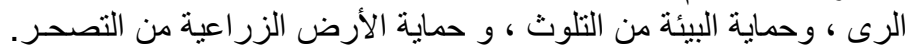

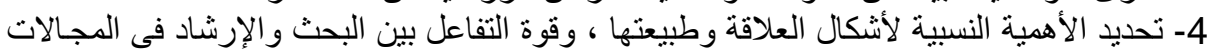

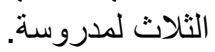
5- التعرف على معنويـة الفروق بين تقدير ات المبحوثين لدرجات أشكال وطبيعـة العلاقـة ، وقوة

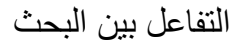

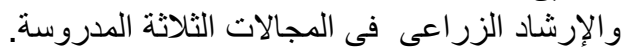

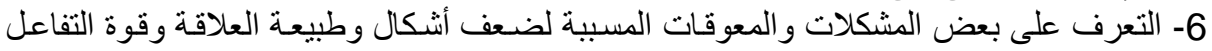
بين البحث و الإرشاد الزر اعى فى الإرثاد المات الثلاث المدروسة ، من وجهة نظر المبحوثين.

\section{فروض البحـث}

لتحقيق الهوف البحتى الخامس ، تم صياغة الفروض البروض البحثية و الإحصائية التالية :

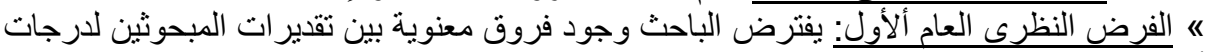

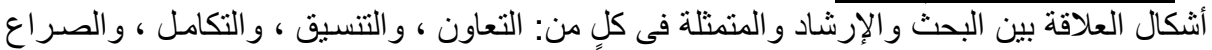

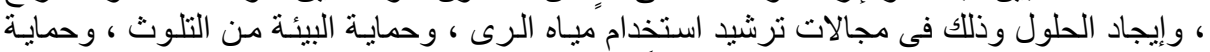
الأرض الزراد الطية من التصحر - كل منها منفرداً على حده. 


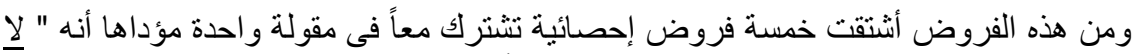

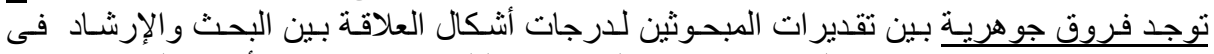

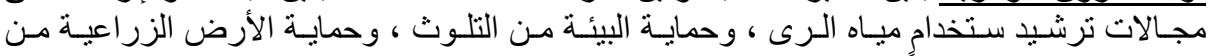

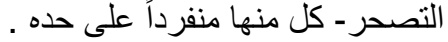

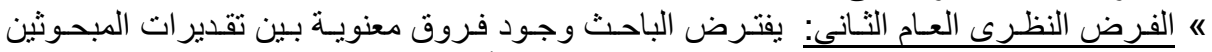

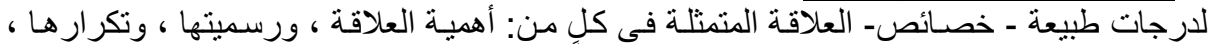

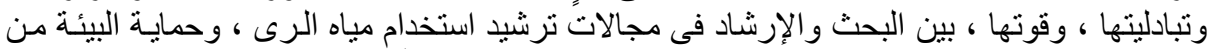

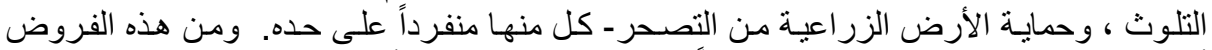

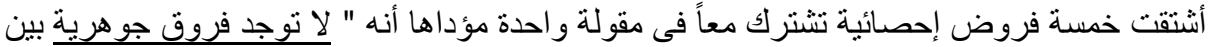

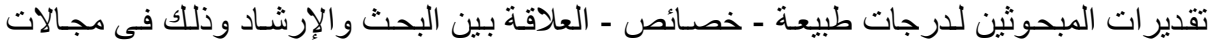

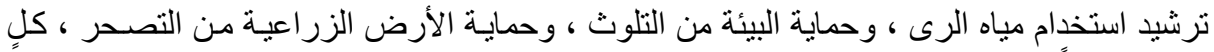

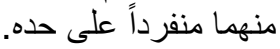
« الفرض النظرى العام الثالث: يفترض الباحث الثاء وجود فروق معنوية بين تقدير ات المبحوثين لدرجات

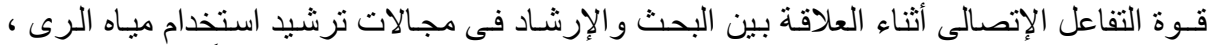

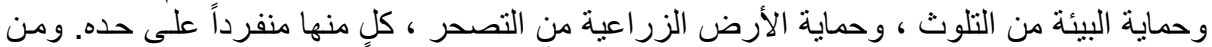

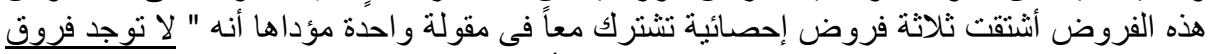

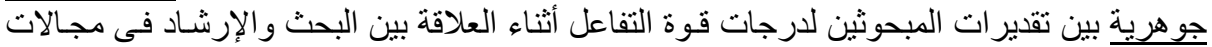

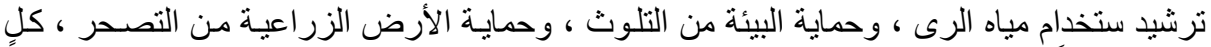

\section{الاستعر اض المرجعى}

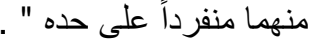

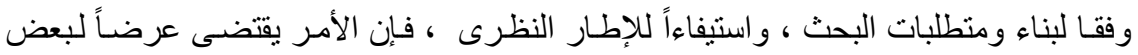

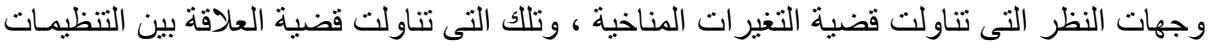

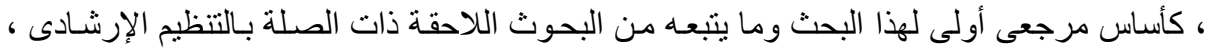

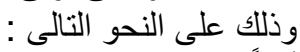

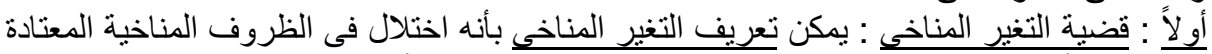

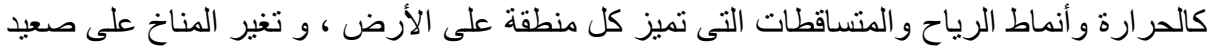

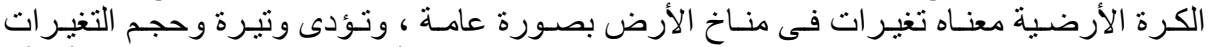

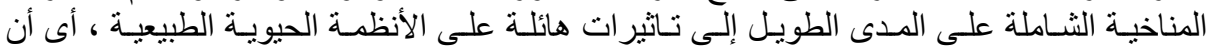

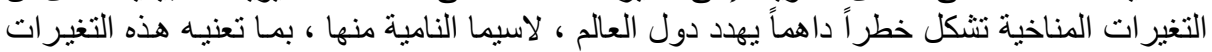

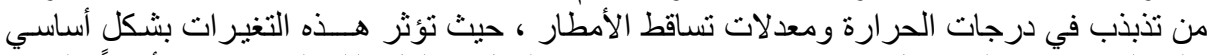

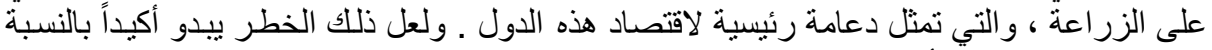

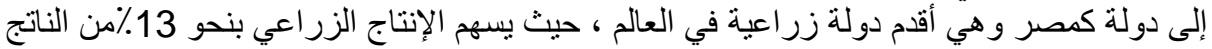

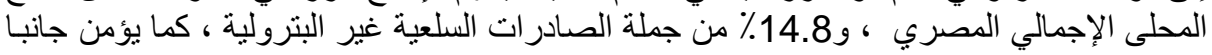

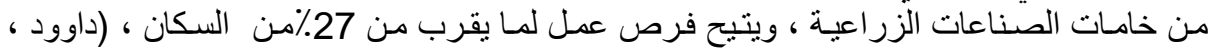
. (2014

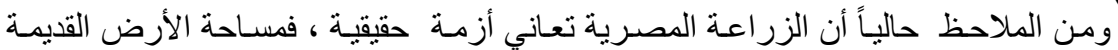

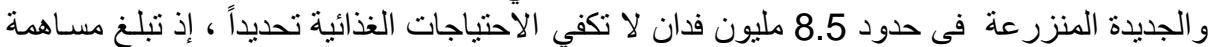

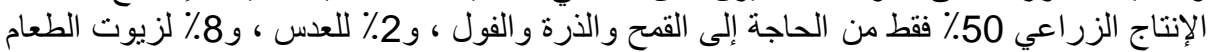

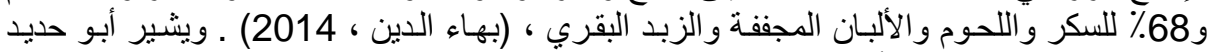

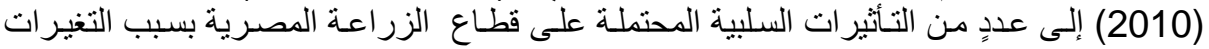
المناخية ومنها مايلى : المى

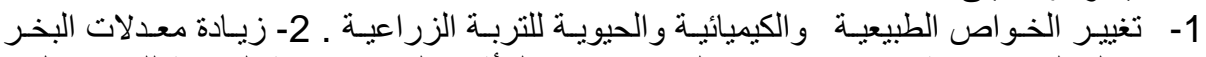

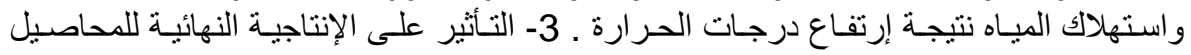


المصرية لاسيما الاستر اتيجية منها ـ 4- فى ظل التغير ات المناخية ، تنبأت بعض الدر اسـات باحتمـال

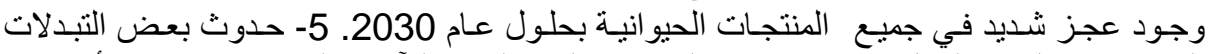
الوظيفية في النبات العائل من جهة وتغيير الوظائف الفسيولوجية للآفات الحشرية من جهة أنسة أخرى ،

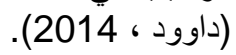

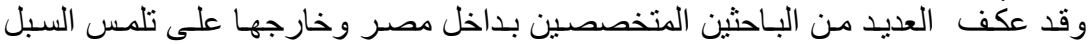

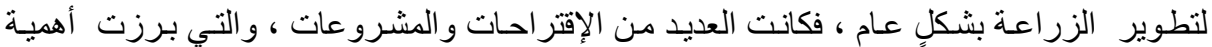

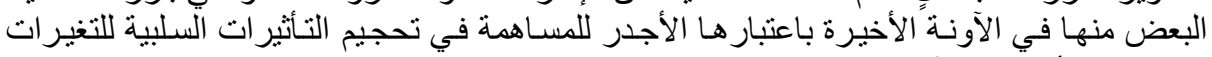

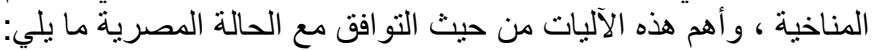

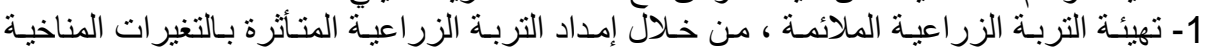

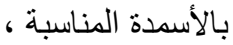
ومعالجتها بإضافة محسنات للتربة للوصول إلى الحاجات الأساسية للإنبات أو باستصلاح أر اضي جديدة لديها قدرة

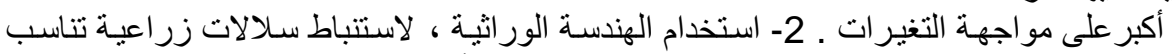

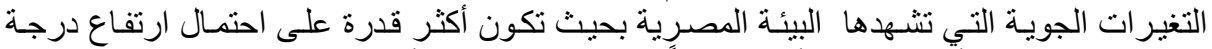

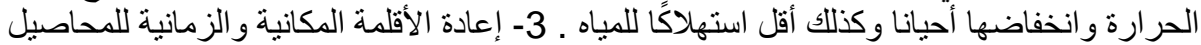

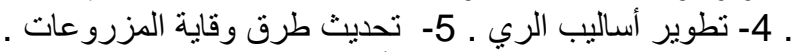

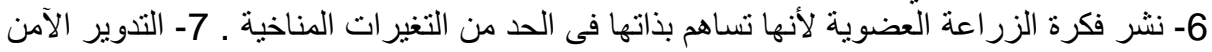

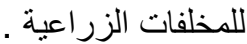

8- تحسين طرق التخزين. 9- الإنمام بالر عاية البيطرية.

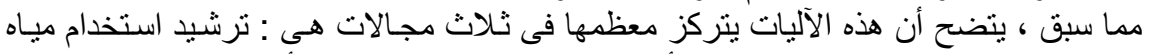

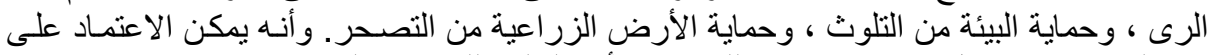

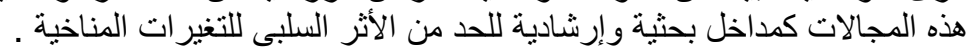

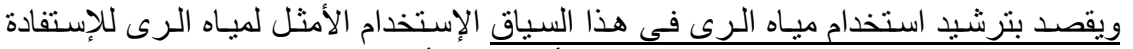

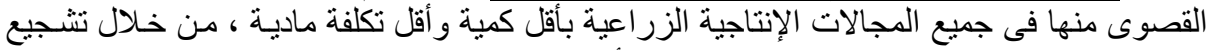

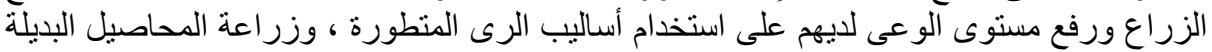

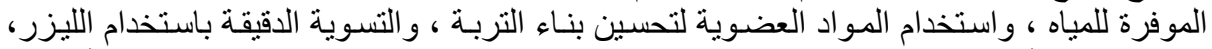

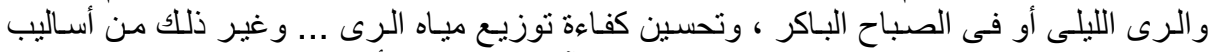

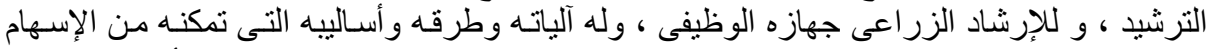

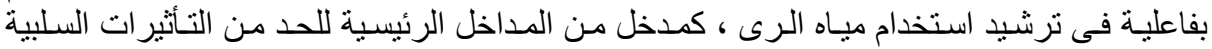

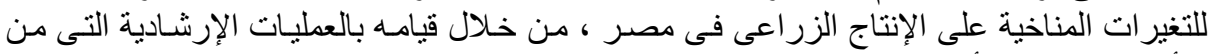

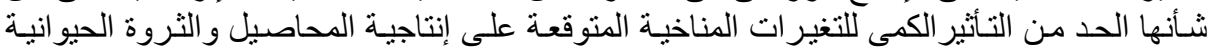

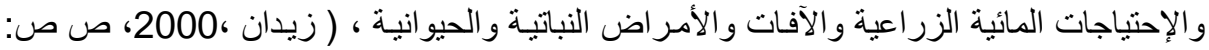

(44-37

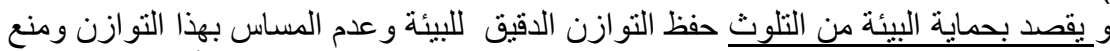

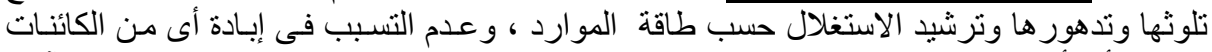

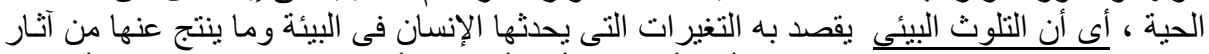

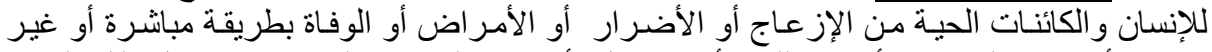

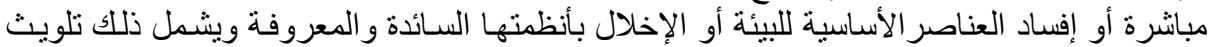

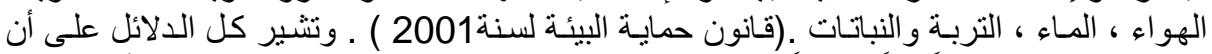

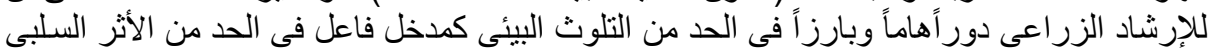

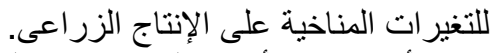

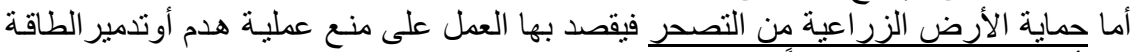

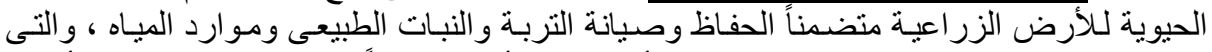

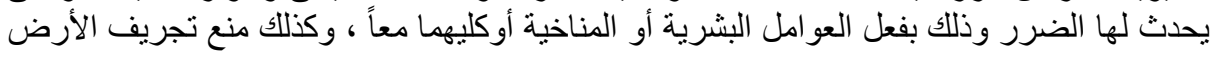




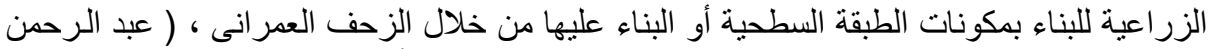

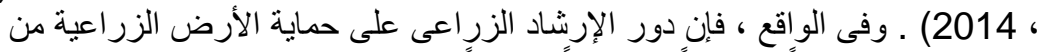

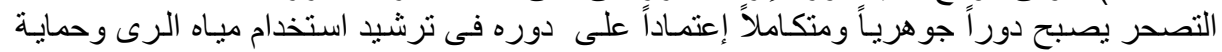
البيئة من التلوث .

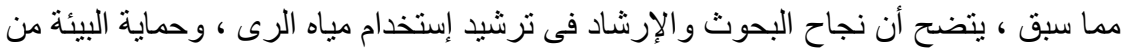

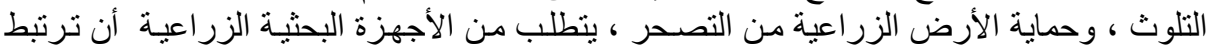

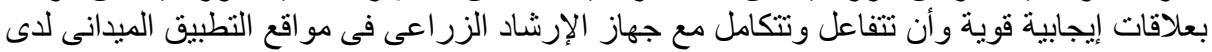

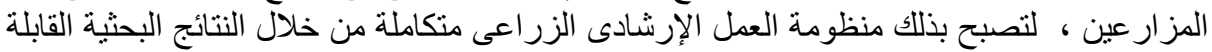

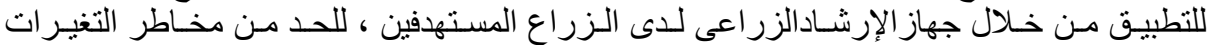

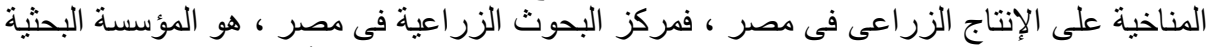

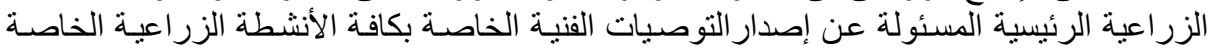

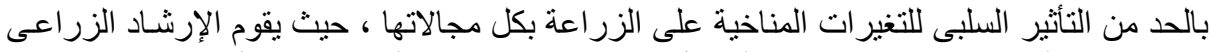

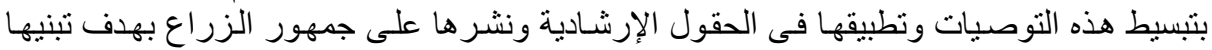
وتطبيقها فى حقو لهم .

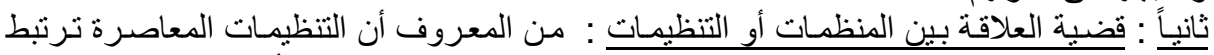

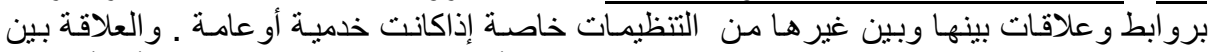

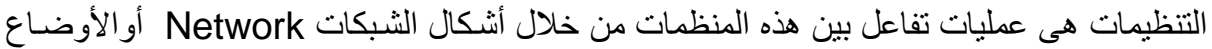

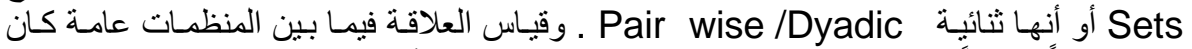

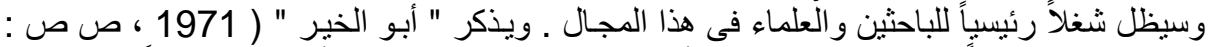

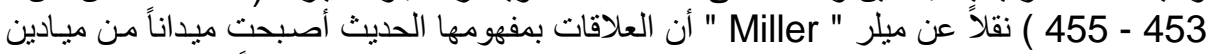

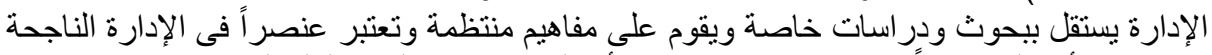

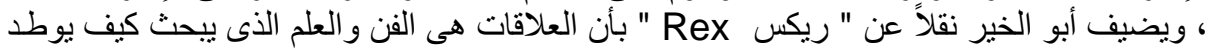

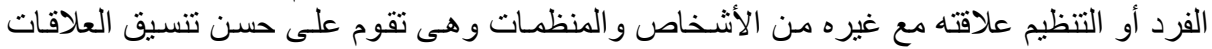

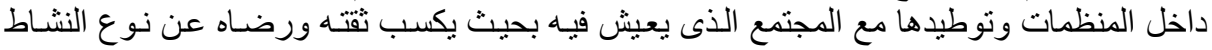

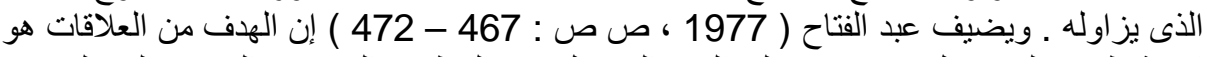

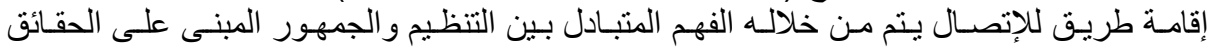

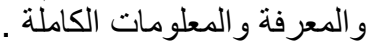

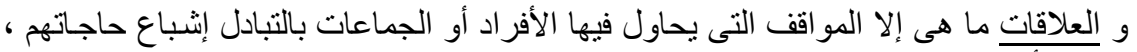

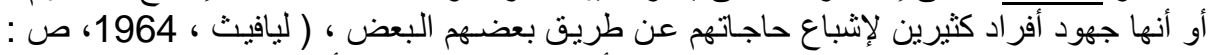

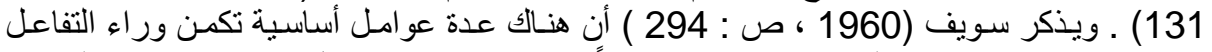

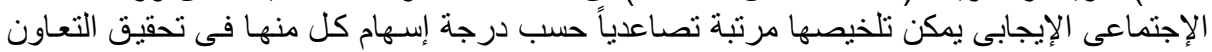

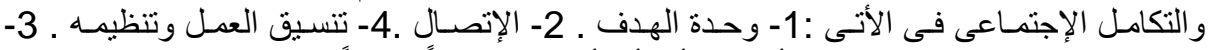

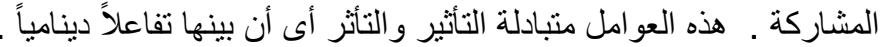

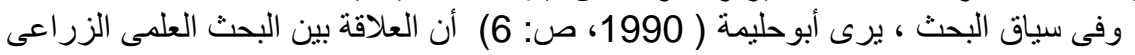

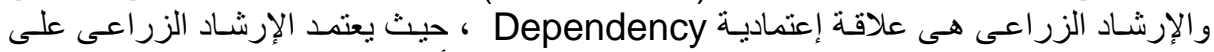

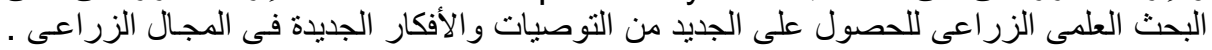

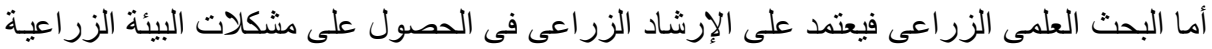

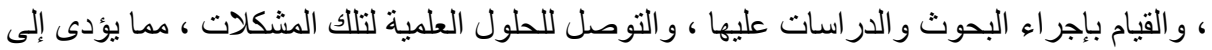

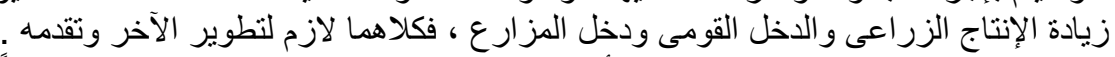

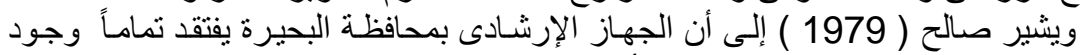

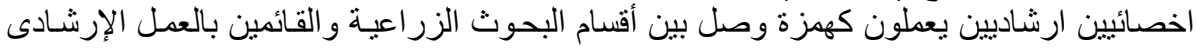

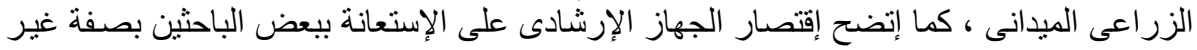

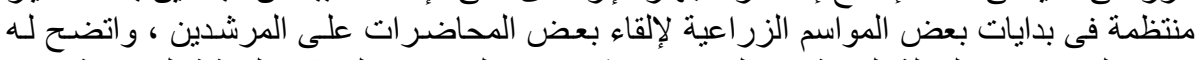

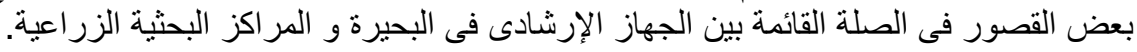




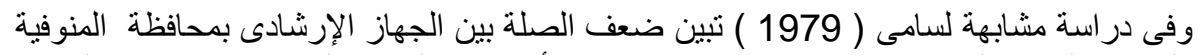

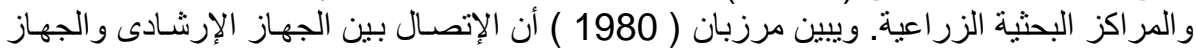

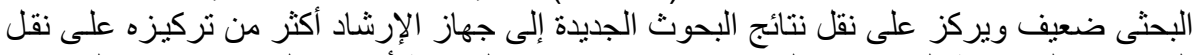

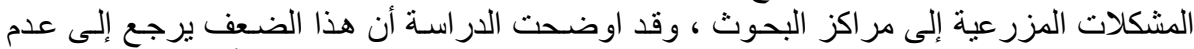

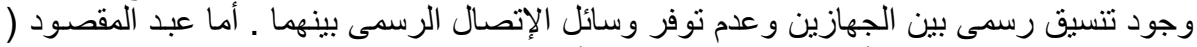

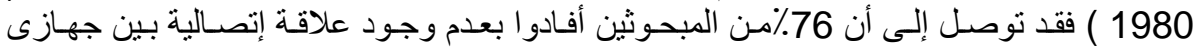

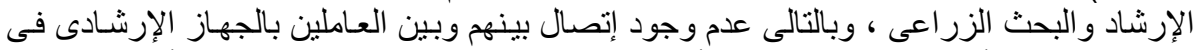

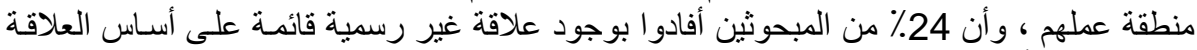

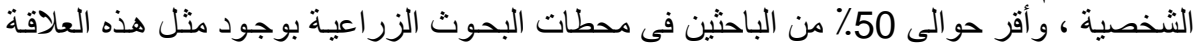

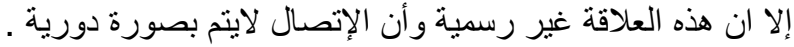

\section{المنهج و الطريقة البحثية}

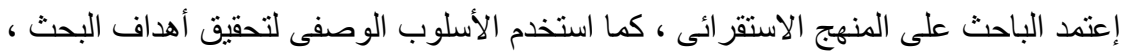

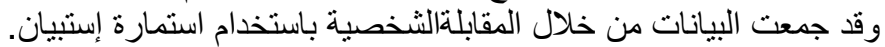

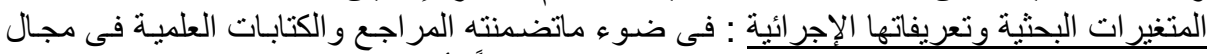

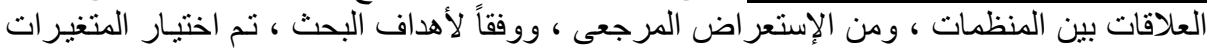

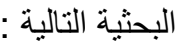

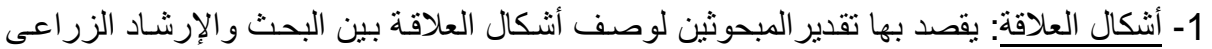

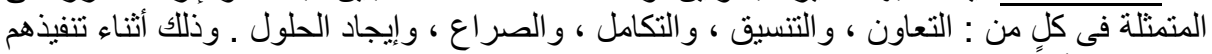

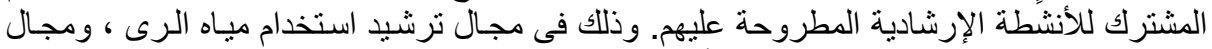

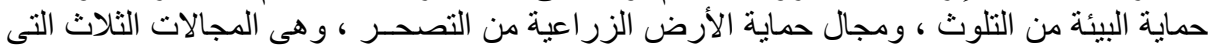
تضمنتها الدر اسة.

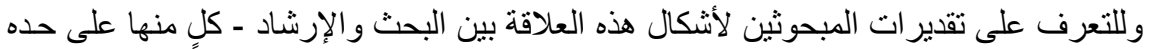

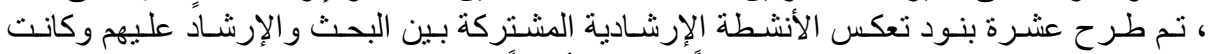

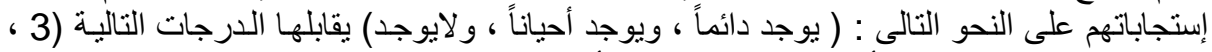

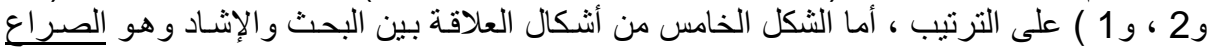

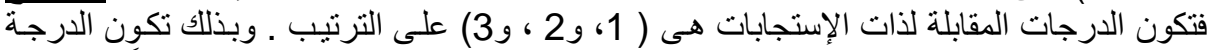

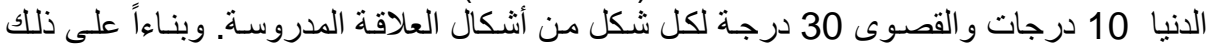
أمكن تقسيم الدرجات المعبرة عن كل شكل من أشكال العلاقة إلى ثنلاث فئسات هـى :

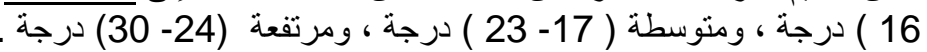

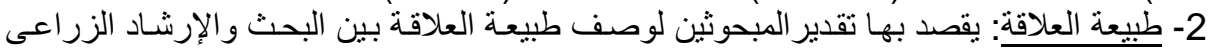

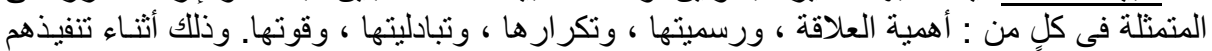

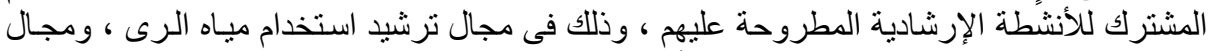

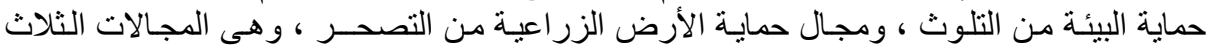
للار اسة.

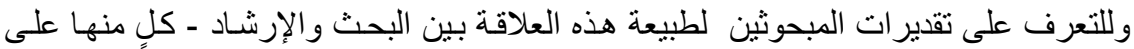

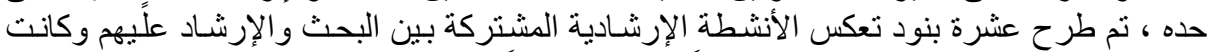

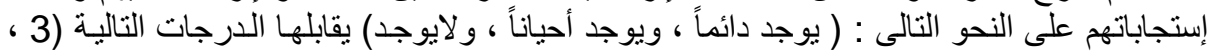

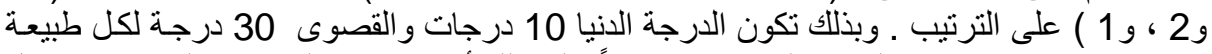

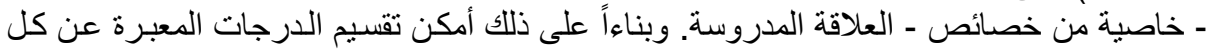

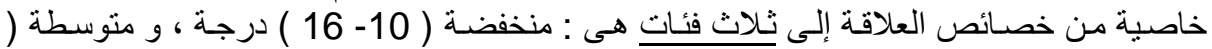

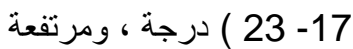
(24) 


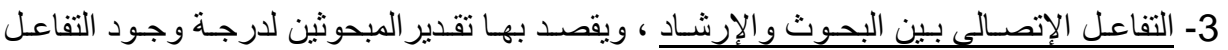

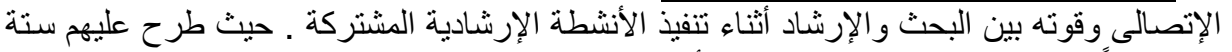

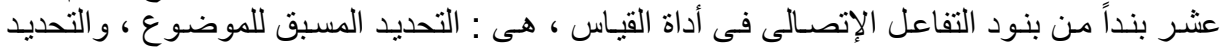

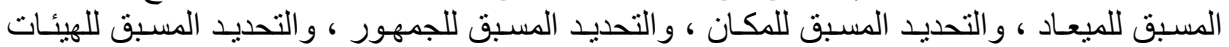

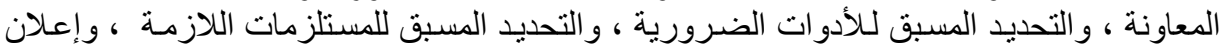

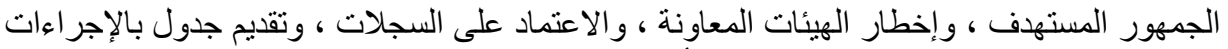

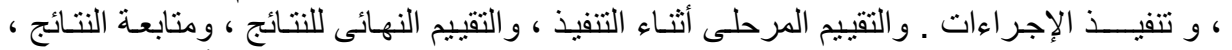

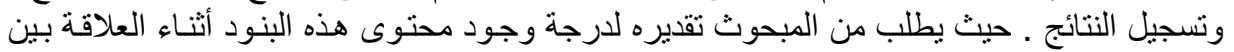

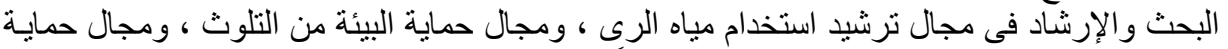

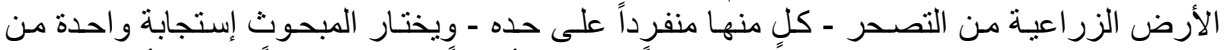

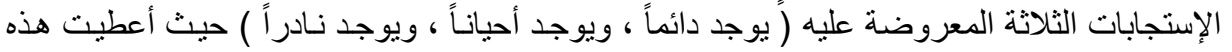

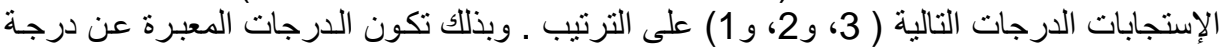

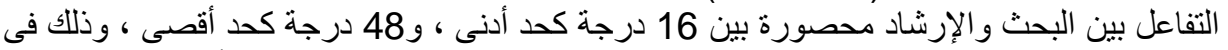

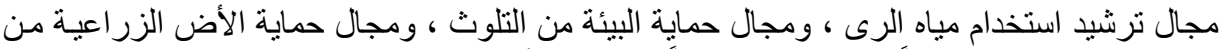

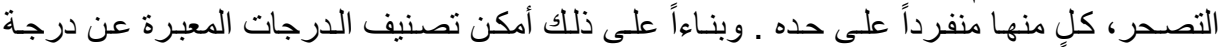

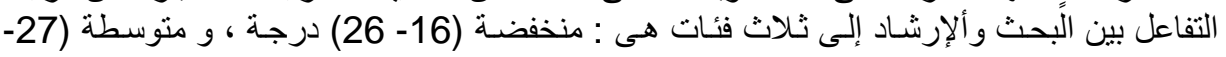

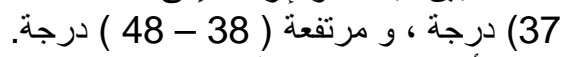

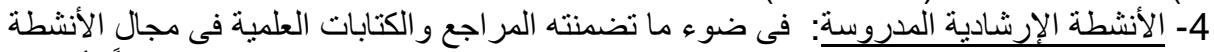

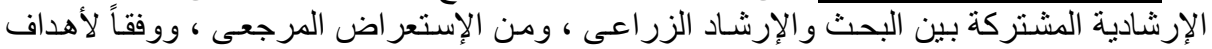

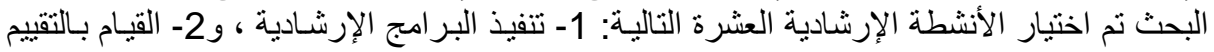

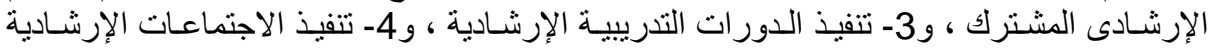

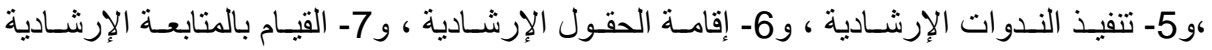

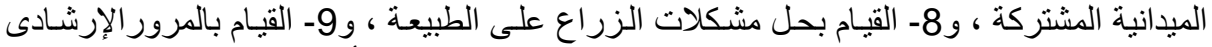

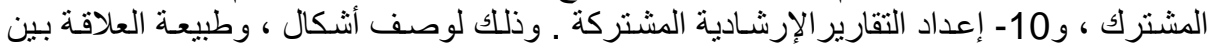
البحث و الإرشاد.

5- الثاملة والعينة البحثية : اشتمل هذا البحث علي شاملتين ، الأولى : تشمل الأخصائيين الإرشاديين

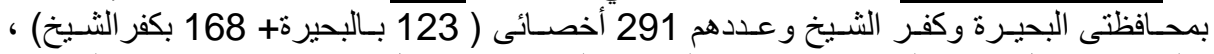

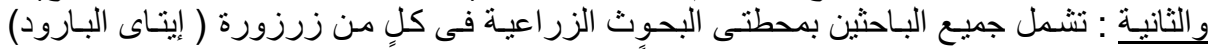

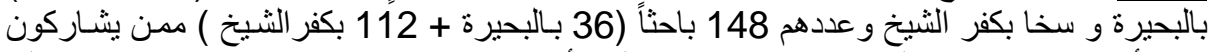

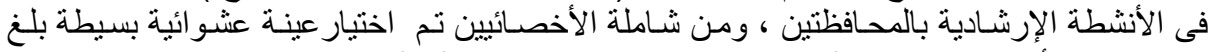

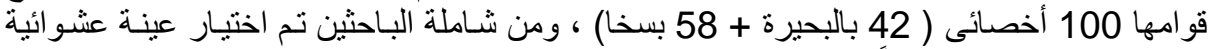

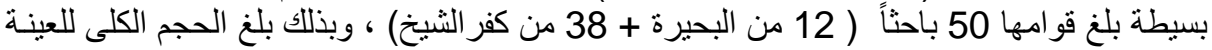

البحثية 150 مفردة بحثية ، بنسبة تمثيل مقدار ها 34\% تقريباً لكل شـاملة من شـاملتى الدر اسـة ، وذلك على النحو الموضـح فى جدول(1)

جولى (1) : الثاملة و العنية المختارة بمحافظتي الار اسلة جدول (1) - (1)

\begin{tabular}{|c|c|c|}
\hline عدد الباحثين & عدد الأخصائيين & المحافظة \\
\hline 36 & 123 & البحيرة ( إيتاى البارود ) \\
\hline 112 & 168 & كفر الشيخ (سخا) \\
\hline 148 & 291 & الشاملة العدادية \\
\hline 50 & 100 & حجم العينة / شاملة \\
\hline$\% 33.8$ & $\% 34.4$ & نسبة تمثيل العينة في للشاملة \\
\hline
\end{tabular}


6- الأساليب الإحصائية : نم الإستعانة بـا لأدوات و الأسـاليب التالية لتحليل البيانات ، عـلام (1985، ص ص: 107- 108 108 ): 1- المنوسط الحسابي لاستخر اج متوسط الإجابات. 2- الانحر اف المعياري لاستخر اج التشتت عن الاوساط الحسابية.

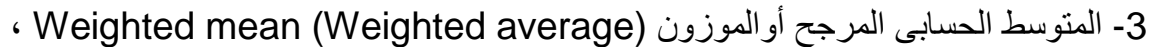

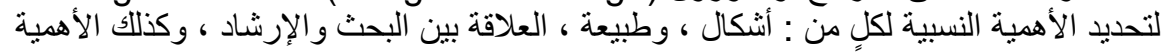

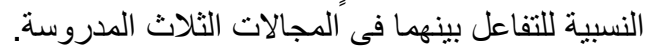

مجموع [ التكرارات × أوز انها ] مجموع الأوزان

4- إختبار (F) لتحليل التباين بين تقدير ات المبحوثين لدرجات كلٍ من : أشكال العلاقة ، وطبيعتها ، ومدى التفاعل بين البحث و الإرشاد - كل منها منفرداً على حده- فى كل مجال من المجالات الثلاث المدروسة.

\section{عرض النتائج البحثية ومناقثتنها}

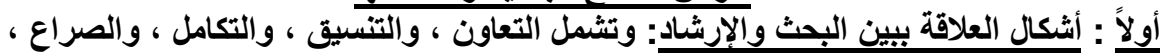
وإيجاد الحلول : الدكل العلاد.

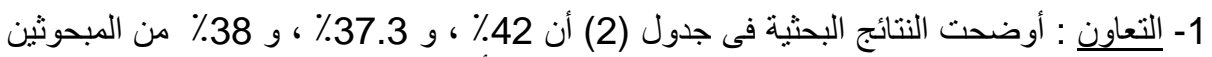

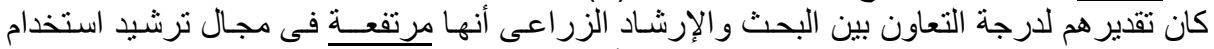

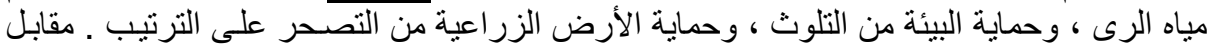

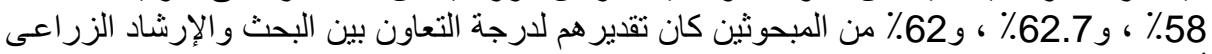

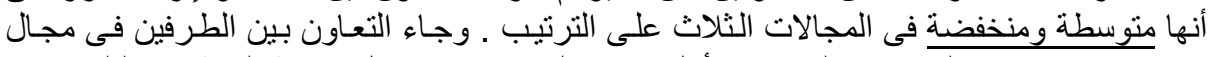

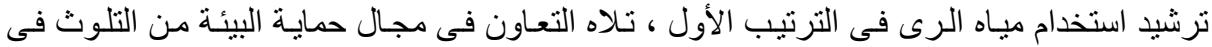

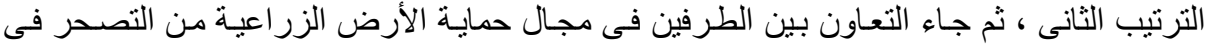

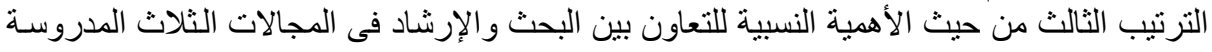
جدول ( 2 ) : توزيع المبحوثين وفقاً لتقديرهم لارجة التعاون بين البحث والإرشـاد الزراعى فى

\begin{tabular}{|c|c|c|c|c|c|c|c|}
\hline \multicolumn{2}{|c|}{ الزرال حمية من التصدر } & \multicolumn{2}{|c|}{ مجال حماية البيئة من } & \multicolumn{2}{|c|}{ مجال ترشيد استخداممياه } & \multirow{2}{*}{\multicolumn{2}{|c|}{ درجة التعاون }} \\
\hline$\%$ & 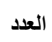 & $\%$ & 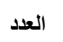 & $\%$ & 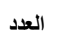 & & \\
\hline 27.3 & 41 & 20.0 & 30 & 16.7 & 25 & $(16$ & - منخفضة (10 - \\
\hline 34.7 & 52 & 42.7 & 64 & 41.3 & 62 & $(23$ & ـ متوسطة (17 - \\
\hline 38.0 & 57 & 37.3 & 56 & 42.0 & 63 & $(30$ & ـ مرتفعـة ( 24 - \\
\hline 100 & 150 & 100 & 150 & 100 & 150 & المجموع & \\
\hline \multicolumn{2}{|c|}{6.78 درجة } & \multicolumn{2}{|c|}{6.2} & \multicolumn{2}{|c|}{5.25} & \multicolumn{2}{|l|}{ ـ الإنحر اف المعيارى } \\
\hline \multicolumn{2}{|c|}{20.87 درجة } & \multicolumn{2}{|c|}{21.55 درجة: } & & \multicolumn{2}{|l|}{ ـ المتوســـ الحسابى } \\
\hline \multicolumn{2}{|c|}{ 5 52.7 درجة } & \multicolumn{2}{|c|}{54.3 درجة } & \multicolumn{2}{|c|}{ 56.3 درجة } & \multicolumn{2}{|l|}{ 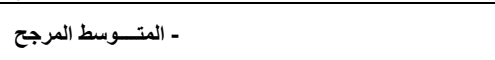 } \\
\hline \multicolumn{2}{|c|}{3} & \multicolumn{2}{|c|}{2} & \multicolumn{2}{|c|}{1} & \multicolumn{2}{|c|}{ ـ الأهمية النسبية للتعاون بين البحث و الإرشاد } \\
\hline
\end{tabular}




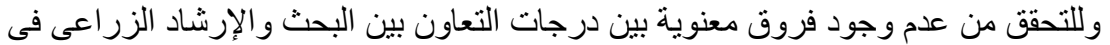

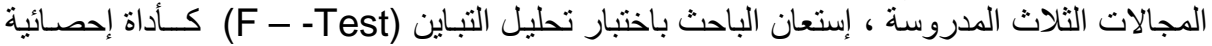

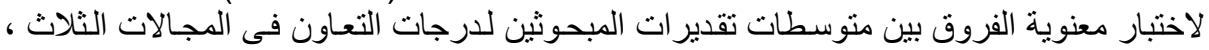

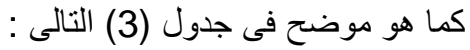

جدول (3): تحليل التباين (f) بين تقديرات المبحوثين لارجات التعاون بين البحث والارشاد

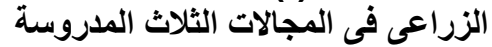

\begin{tabular}{|c|c|c|c|c|c|c|}
\hline المعنوية & قالمسيمة فية & التباين & الحرية & الانحر افات مربع & مصدرالاختلافات & شكل العلاقة \\
\hline 0.111 & 2.210 & $\begin{array}{l}80.889 \\
36.600\end{array}$ & $\begin{aligned} 2 & =\text { بقام:447 } \\
449 & \text { مبط }\end{aligned}$ & $\begin{array}{r}161.778 \\
16360.420 \\
16522.198\end{array}$ & 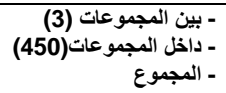 & 1- التعاون \\
\hline
\end{tabular}

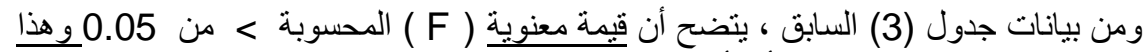

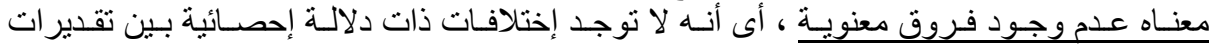

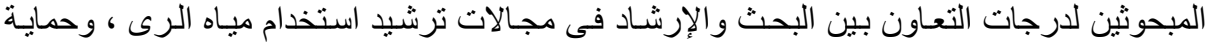

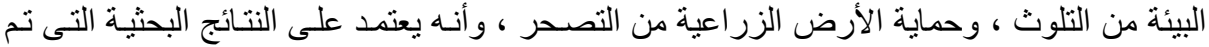

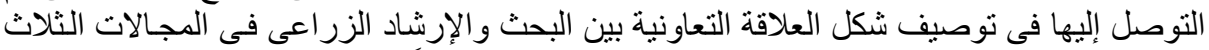

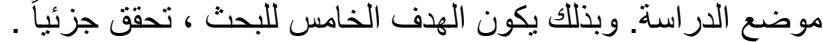

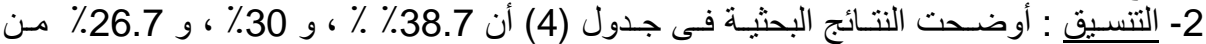

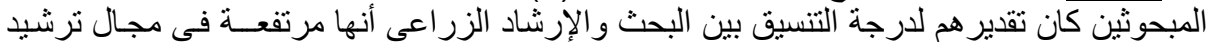

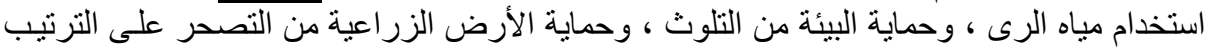

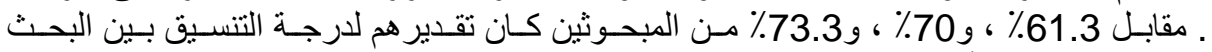

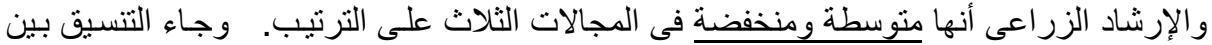

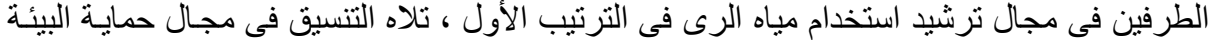

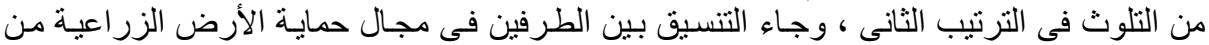

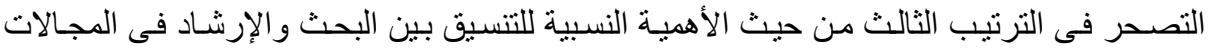
الثلاث المدروسة. جدول ( 4 ) : توزيع المبحوثين وفقاً لتقديرهم لارجة التنسيق بين البحث والإرشاد الزراعى فى

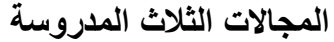

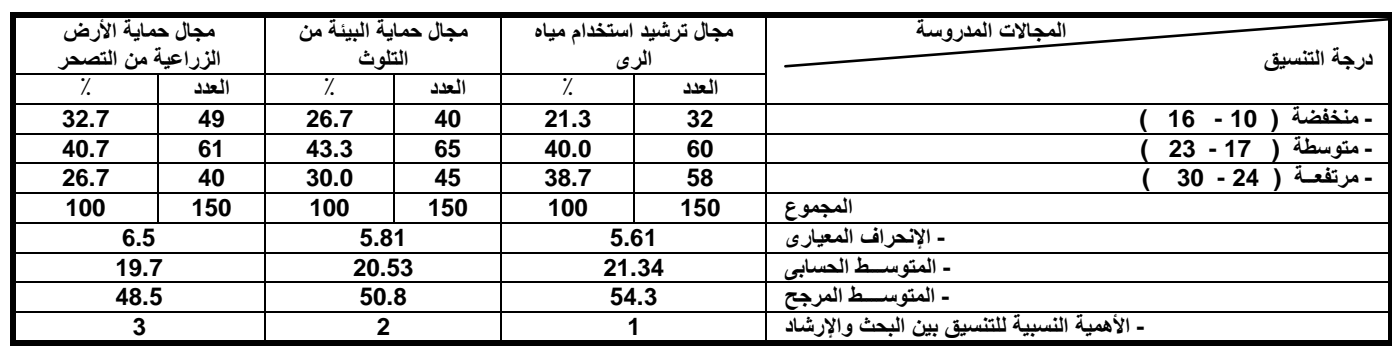

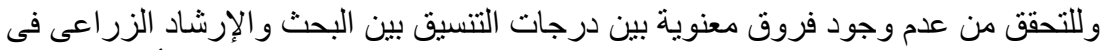

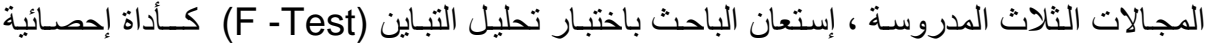


لاختبار معنوية الفروق بين منوسطات تقدير ات المبحوثين لدرجات التنسيق فى المجالات الثلاث ،

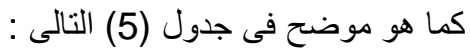

جدول ( 5 ) : تحليل التباين (f) بين تقديرات المبحوثين لارجات التسيق بين البحث والارشاد الزراعى فى المجالات الثلاث المدروسة

\begin{tabular}{|c|c|c|c|c|c|c|}
\hline المعنوية & قالمسيوبة ف & التباين & لدرجات & مجموع مربع الانحرافات & مصدرالاختلافات & شكل العلاقة \\
\hline 0.069 & 2.691 & $\begin{array}{l}96.002 \\
35.673\end{array}$ & $\begin{aligned} & 2==\text { بقام=447 } \\
& 449=\end{aligned}$ & $\begin{array}{r}192.004 \\
15945.858 \\
16137.858\end{array}$ & 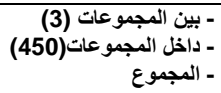 & 2- التنسيق \\
\hline
\end{tabular}

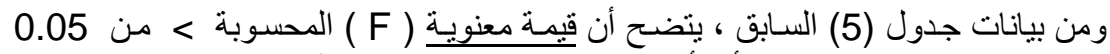

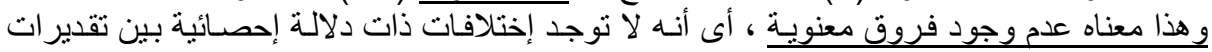

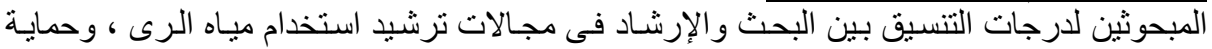

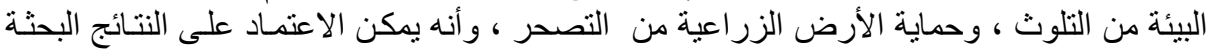

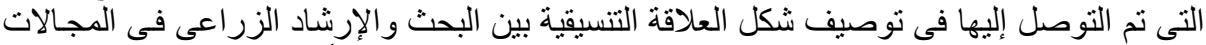

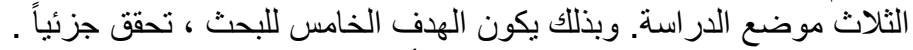

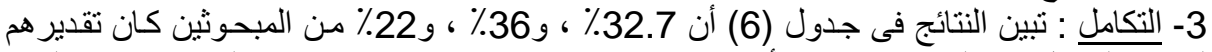

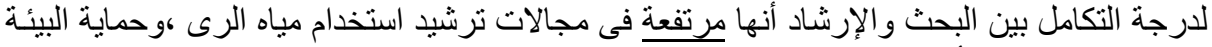

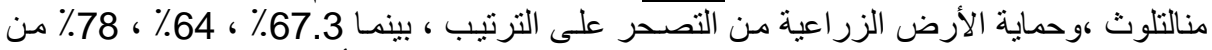

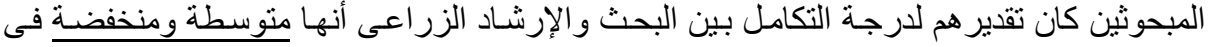

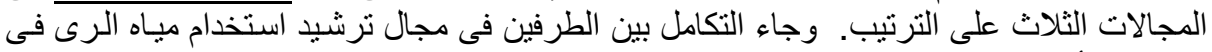

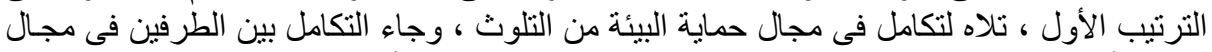

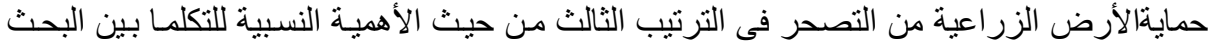

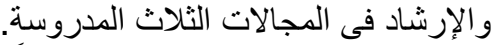
جدول ( 6 ) : توزيع المبحوثين وفقاً لتقديرهم لارجة التكامل بين البحث والإرشاد الزراعى فى المجالات الثلاث المدروسة المبن وفنات

\begin{tabular}{|c|c|c|c|c|c|c|c|}
\hline \multicolumn{2}{|c|}{ مجال حماية الأرض } & \multicolumn{2}{|c|}{ مجال حماية البيئة من } & \multicolumn{2}{|c|}{ مجال ترشيد استخدام مياه } & \multirow{2}{*}{\multicolumn{2}{|c|}{ المجالات المدروسة }} \\
\hline$\%$ & العلد & $\%$ & العدد & $\%$ & العلد & & \\
\hline 35.3 & 53 & 26.7 & 40 & 21.3 & 32 & $(16-10$ & - | - | منخفضة \\
\hline 42.7 & 64 & 37.3 & 56 & 46.0 & 69 & $(23-17$ & - متوسطة \\
\hline 22.0 & 33 & 36.0 & 54 & 32.7 & 49 & $(30-24$ & - مرتفعـة | - مات \\
\hline 100 & 150 & 100 & 150 & 100 & 150 & 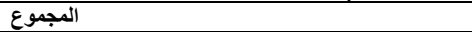 & \\
\hline \multicolumn{2}{|c|}{6.78} & \multicolumn{2}{|c|}{6.02} & \multicolumn{2}{|c|}{5.25} & - الإنحراف المعيارى & \\
\hline \multicolumn{2}{|c|}{20.87} & \multicolumn{2}{|c|}{21.55} & \multicolumn{2}{|c|}{22.35} & ـ ـ المتوســط الحسابي & \\
\hline \multicolumn{2}{|c|}{$\begin{array}{c}46.7 \\
3\end{array}$} & \multicolumn{2}{|c|}{52.3} & \multicolumn{2}{|c|}{52.8} & - المتوســ المرجح & \\
\hline \multicolumn{2}{|c|}{3} & \multicolumn{2}{|c|}{2} & \multicolumn{2}{|c|}{1} & ـ الأهمية النسبية للتكامل بين البحث والإرشاد & \\
\hline
\end{tabular}

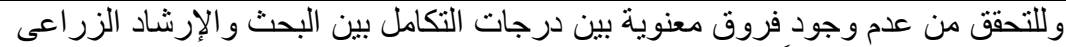

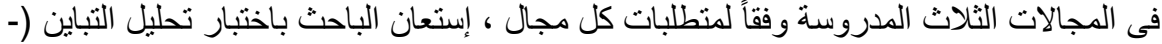
(F- Test

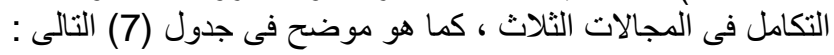


جدول ( 7 ) : تحليل التباين (f) بين تقديرات المبحوثين لارجات التكامل بين البحث والارشاد

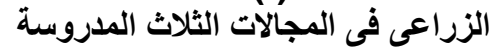

\begin{tabular}{|c|c|c|c|c|c|c|}
\hline المعنوية & قالمسمة فة & التباين & الدرجية & الانحر افات مربع & مصدرالاختلافات & شكل العلاقة \\
\hline 0.006 & 5.117 & $\begin{array}{l}186.500 \\
36.026\end{array}$ & $\begin{array}{l}2=\text { بقام=447 = } 447 \\
449\end{array}$ & $\begin{array}{r}373.000 \\
1610.500 \\
16176.500\end{array}$ & 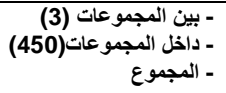 & 3- التكامل \\
\hline
\end{tabular}

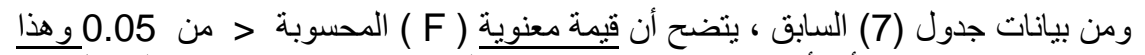

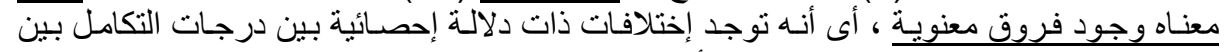

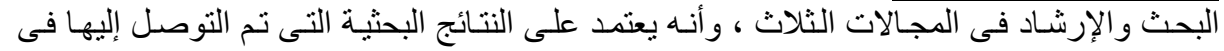

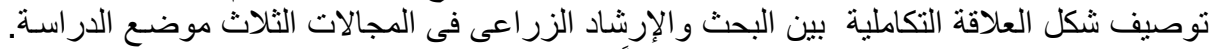

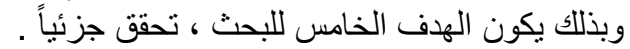

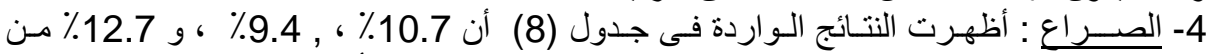

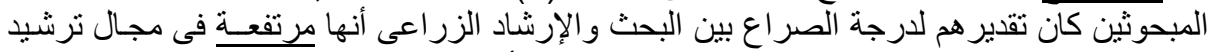

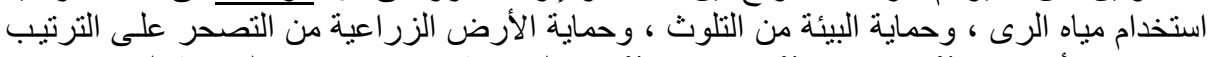

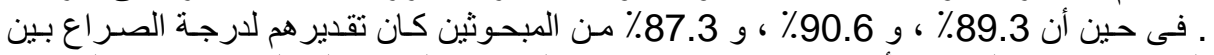

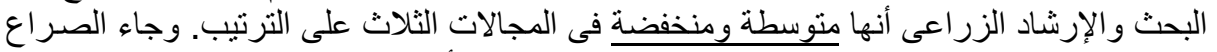

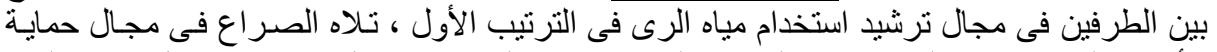

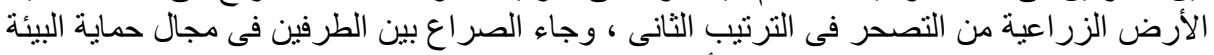

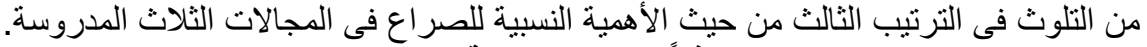

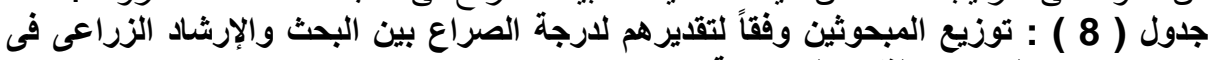
المجالات الثلاث المدروسة

\begin{tabular}{|c|c|c|c|c|c|c|}
\hline \multicolumn{2}{|c|}{ الزراعية من التصحة الأرضر } & \multicolumn{2}{|c|}{ مجال حمايةً البيئة من } & \multirow{2}{*}{\multicolumn{2}{|c|}{ مجال ترشيد استخدام مياه }} & \multirow{2}{*}{ درجة الصراع } \\
\hline$\%$ & | العدد & $\%$ & العدد & & & \\
\hline 68.0 & 102 & 71.3 & 107 & 71.3 & 107 & - منخفضة ( 24 - 30 ) \\
\hline 19.3 & 29 & 19.3 & 29 & 18.0 & 27 & - متوسطة ( 17 - 17 - 23 ) \\
\hline 12.7 & 19 & 9.4 & 14 & 10.7 & 16 & - مرتفعـة (10 - 16 - \\
\hline 100 & 150 & 100 & 150 & 100 & 150 & 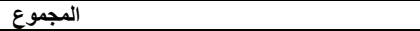 \\
\hline \multicolumn{2}{|c|}{6.48} & \multicolumn{2}{|c|}{5.82} & \multicolumn{2}{|c|}{6.13} & - الإنحراف المعيارى \\
\hline \multicolumn{2}{|c|}{25.01} & \multicolumn{2}{|c|}{25.61} & \multicolumn{2}{|c|}{25.30} & ـ ـ المتـــوسط الحسابي \\
\hline \multicolumn{2}{|c|}{36.2} & \multicolumn{2}{|c|}{34.5} & \multirow{2}{*}{\multicolumn{2}{|c|}{$\frac{34.8}{1}$}} & ــ المتوســــ المرجع \\
\hline \multicolumn{2}{|c|}{2} & \multicolumn{2}{|c|}{3} & & & ـ الأهمية النسبية للصراع بين البحث والإرشاد \\
\hline
\end{tabular}

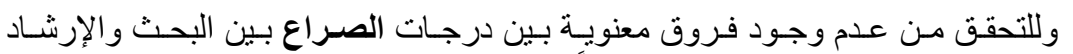

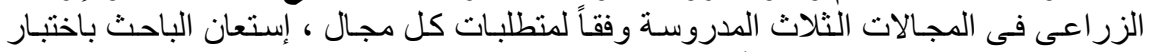

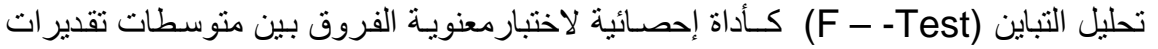

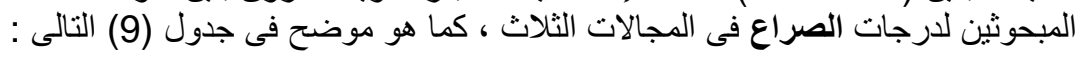

جدول (9) : تحليل التباين (f) بين تقديرات المبحوثين لارجات الصراع بين البحث والارشاد

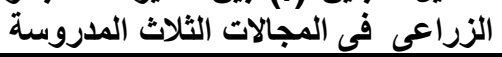

\begin{tabular}{|c|c|c|c|c|c|c|}
\hline المسنوية & قالمسيمة فة & التباين & الدرجية & مجموع مربع & مصدر الاختلافات & شكل العلاقة \\
\hline 0.700 & 0.357 & $\begin{array}{l}13.509 \\
37.832\end{array}$ & 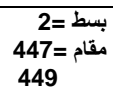 & $\begin{array}{r}27.018 \\
16911.047 \\
16938.064\end{array}$ & ـ ـ ـ بين المجموعات (350) المجموع (450) & 4- الصراع \\
\hline
\end{tabular}




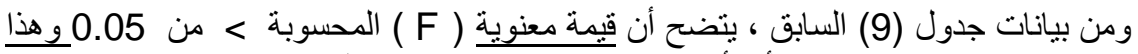

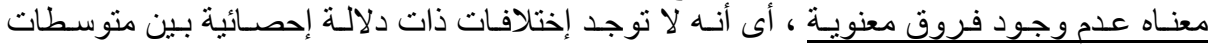

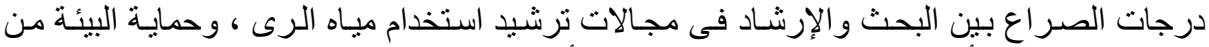

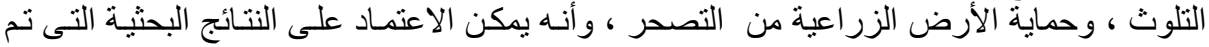

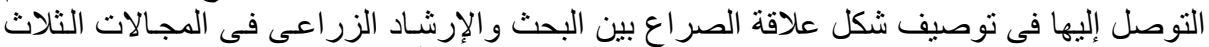

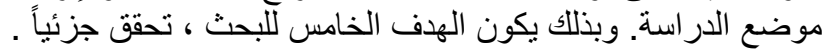

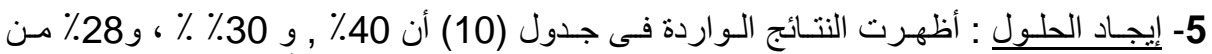

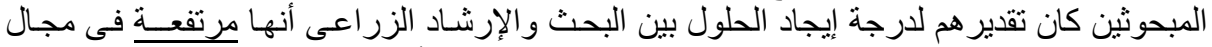

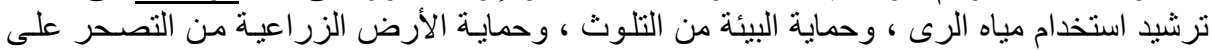

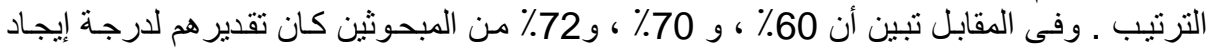

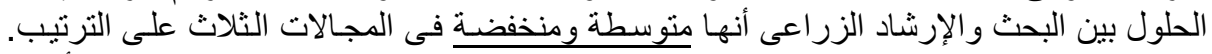

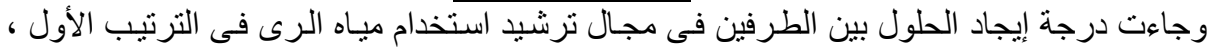

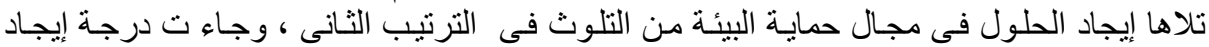

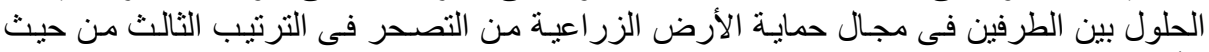

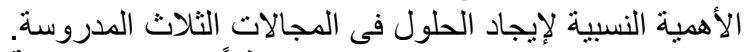
جدول ( 10 ) : توزيع المبحوثين وفقاً لتقديرهم لارجة إيجاد الحلول الأل بين البحث والإرشاد

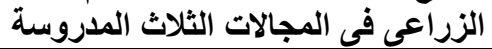

\begin{tabular}{|c|c|c|c|c|c|c|}
\hline \multicolumn{2}{|c|}{ الزجالية حماية الأرضح } & \multicolumn{2}{|c|}{ مجال حماية البيئة } & \multicolumn{2}{|c|}{ مجال ترشيا استخدام } & \multirow{2}{*}{ درجة إيجاد الحلول } \\
\hline$\%$ & العدد & $\%$ & العدد & $\%$ & العدد & \\
\hline 26.0 & 39 & 20.0 & 30 & 20.7 & 31 & - منخفضة (10 - 16) \\
\hline 46.0 & 69 & 50.0 & 75 & 39.3 & 59 & - متوسطة ( 17 - 23 - \\
\hline 28.0 & 42 & 30.0 & 45 & 40.0 & 60 & - مرتفعسة ( $24-30)$ \\
\hline 100 & 150 & 100 & 150 & 100 & 150 & 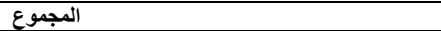 \\
\hline \multicolumn{2}{|c|}{6.43} & \multicolumn{2}{|c|}{5.91} & \multicolumn{2}{|c|}{5.88} & ـ الإحـراف المعيارى \\
\hline \multicolumn{2}{|c|}{19.99} & \multicolumn{2}{|c|}{21.10} & \multicolumn{2}{|c|}{21.37} & - ــ المتوســط الحسابى \\
\hline \multicolumn{2}{|c|}{50.5} & \multicolumn{2}{|c|}{52.5} & \multicolumn{2}{|c|}{54.8} & ـ ـ المتوســـ المرجح \\
\hline \multicolumn{2}{|c|}{3} & \multicolumn{2}{|c|}{2} & \multicolumn{2}{|c|}{1} & - الأهمية النسبية لإيجاد الحلول بين البحث والإرشاد \\
\hline
\end{tabular}

وللتحقق من عدم وجود فروق معنويـة ببن درجـات إيجاد الحلول ببين البحث و الإرشـاد

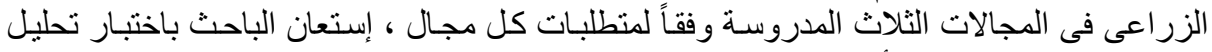

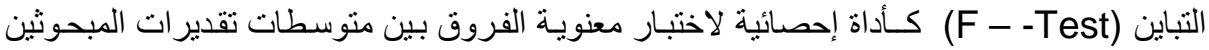

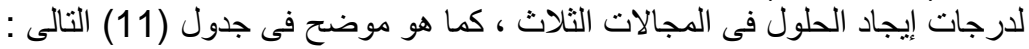

جدول ( 11 ) : تحليل التباين (f) بين تقديرات المبحوثين لارجات إيجاد الحلول بين البحث

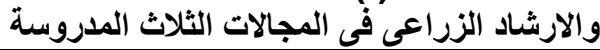

\begin{tabular}{|c|c|c|c|c|c|c|}
\hline المعنوية & قالمسمة فة & التباين & الحرية & الانحرافات مربع & مصدرالاختلافات & شكل العلاقة \\
\hline 0.114 & 2.181 & $\begin{array}{l}80.660 \\
36.978\end{array}$ & $\begin{aligned} 2 & =\text { مقام=447 } \\
449 & \text { مuط }\end{aligned}$ & $\begin{array}{r}161.320 \\
16529.100 \\
16690.420\end{array}$ & 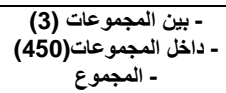 & 5- إيجاد الحلول \\
\hline
\end{tabular}

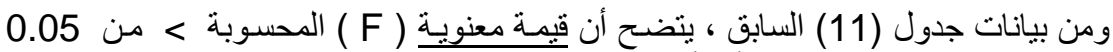

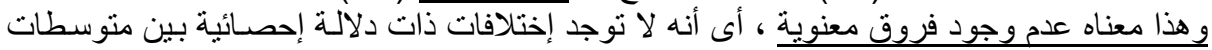

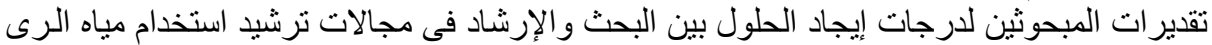




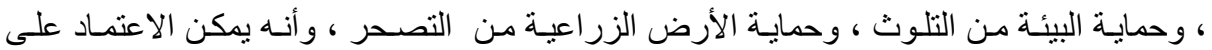

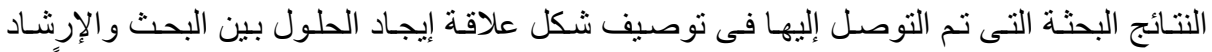

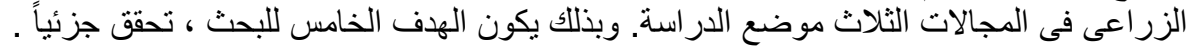

ثثانياً : طبيعة العلاقة ببين البحث والإرشاد : وتشمل أهمية العلاقة ، ورسميتها ، وتكرارها ،

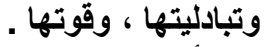

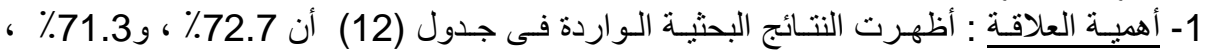

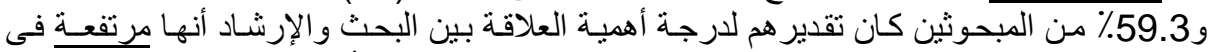

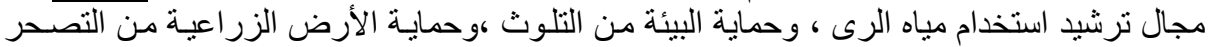

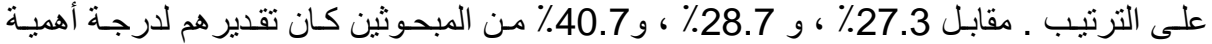

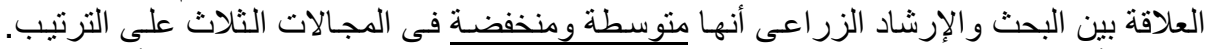

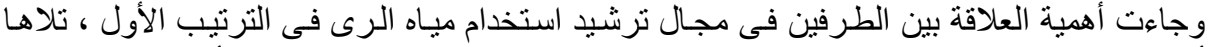

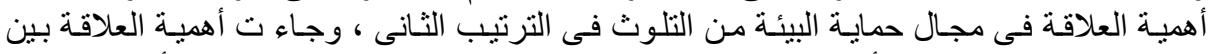

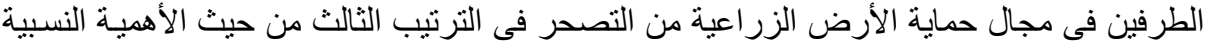

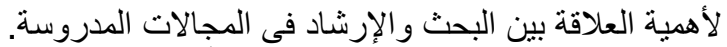

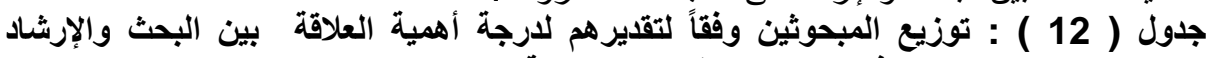

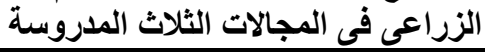

\begin{tabular}{|c|c|c|c|c|c|c|}
\hline \multirow{2}{*}{\multicolumn{2}{|c|}{ مجال حماية الأرض }} & \multirow{2}{*}{\multicolumn{2}{|c|}{ مجال حماية البيئة }} & \multirow{2}{*}{\multicolumn{2}{|c|}{ مجال ترشيا استخدام }} & \multirow[t]{2}{*}{ المجالات المدروسة } \\
\hline & & & & & & \\
\hline$\%$ & العدد & $\%$ & العدد & $\%$ & العدد & لدرجة أهمية العلاقة \\
\hline 14.0 & 21 & 6.0 & 9 & 5.3 & 8 & 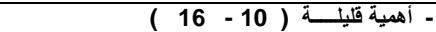 \\
\hline 26.7 & 40 & 22.7 & 34 & 22.0 & 33 & ــ أهمية متوسطة ( 17 - 23 ) \\
\hline 59.3 & 89 & 71.3 & 107 & 72.7 & 109 & - أهمية كبـيرةة ( 24 - 30 ك ) \\
\hline 100 & 150 & 100 & 150 & 100 & 150 & 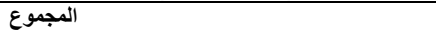 \\
\hline \multicolumn{2}{|c|}{6.56} & \multicolumn{2}{|c|}{5.32} & \multicolumn{2}{|c|}{5.88} & ـ - الإحر اف المعيارى \\
\hline \multicolumn{2}{|c|}{24.07} & \multicolumn{2}{|c|}{25.55} & \multicolumn{2}{|c|}{25.71} & - المتوســ الحسابى \\
\hline \multicolumn{2}{|c|}{61.3} & \multicolumn{2}{|c|}{66.3} & \multicolumn{2}{|c|}{66.8} & - المتوســط المرجح \\
\hline \multicolumn{2}{|c|}{3} & \multicolumn{2}{|c|}{2} & \multicolumn{2}{|c|}{1} & ـ الأهمية النسبية لأهمية العلاقة بين البحث والإرشاد \\
\hline
\end{tabular}

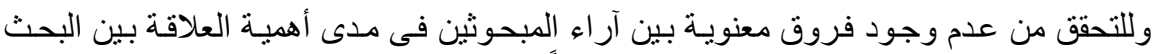

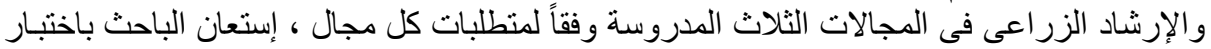

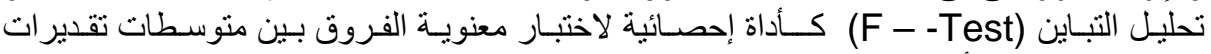

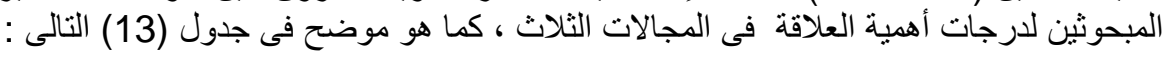

جدول ( 13 ) : تحليل التباين (f) بين تقديرات المبحوثين لارجات أهمية العلاقة بين البحث والارشاد الزراعى في المجالات الثثلاث المدروسة المونة

\begin{tabular}{|c|c|c|c|c|c|c|}
\hline المعنوية & قالمسمة فة & التباين & لدرجات & مجموع مربع الانحر افات & مصدرالاختلافات & طبيعة العلاقة \\
\hline 0.025 & 3.722 & $\begin{array}{c}122.610 \\
32.948\end{array}$ & $\begin{aligned} & 2=4 \\
& 447=\text { مقام } 449 \\
& 449\end{aligned}$ & $\begin{array}{r}161.320 \\
16529.100 \\
16690.420\end{array}$ & 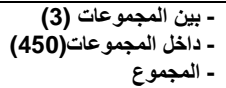 & 2- أهمية العلاقة \\
\hline
\end{tabular}

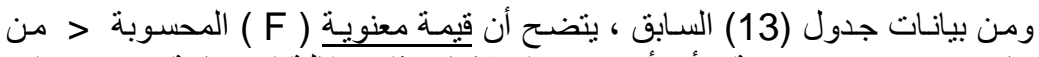

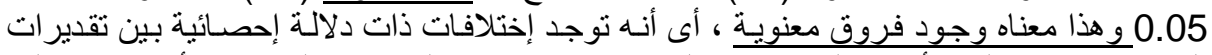

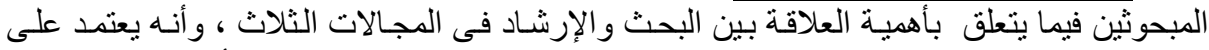

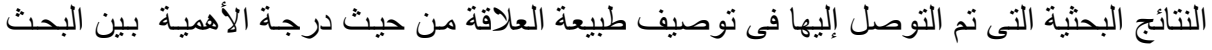


و الإرشاد الزر اعى فى المجالات الثلاث موضع الدراسة. وبذلك يكون الهدف الخامس للبحث ، تحقق جزئياً.

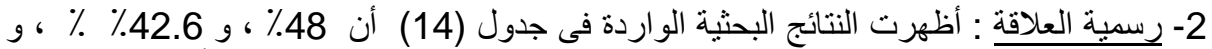

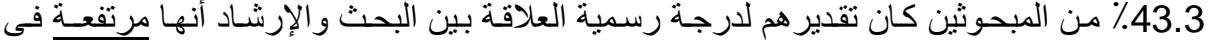

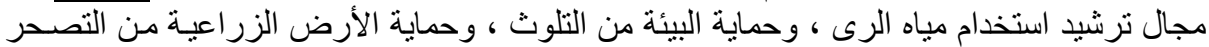

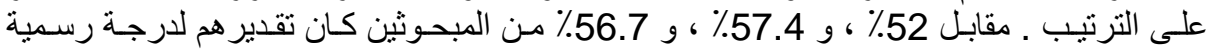

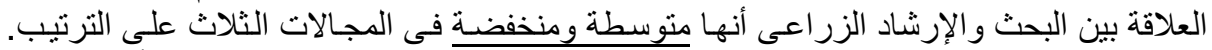

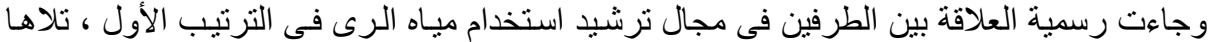

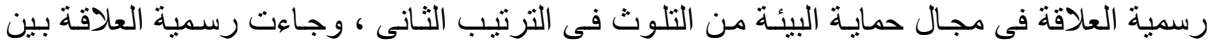

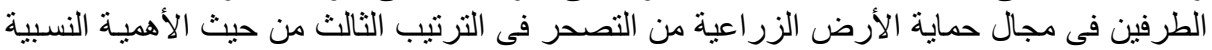

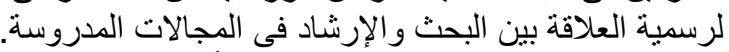

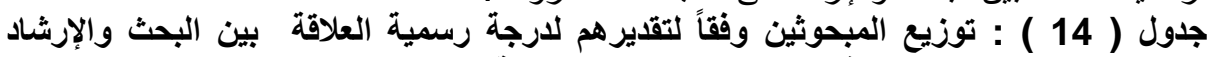

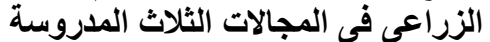

\begin{tabular}{|c|c|c|c|c|c|c|}
\hline \multicolumn{2}{|c|}{ الزرالية مناية الأرضر } & \multicolumn{2}{|c|}{ مجال حماية البيئة } & \multicolumn{2}{|c|}{ مجال ترشياه استخدام } & \multirow{2}{*}{ درجة الرسمية } \\
\hline$\%$ & العدد & $\%$ & العدد & $\%$ & 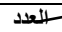 & \\
\hline 18.7 & 28 & 12.7 & 19 & 11.3 & 17 & - منففضة (10 - 16 16) \\
\hline 38.0 & 57 & 44.7 & 67 & 40.7 & 61 & - متوسطة ( 17 - 23 - 23 ) \\
\hline 43.3 & 65 & 42.6 & 64 & 48.0 & 72 & - مرتفعـة ( 24 - 30 ) \\
\hline 100 & 150 & 100 & 150 & 100 & 150 & 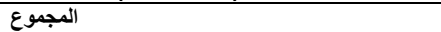 \\
\hline \multicolumn{2}{|c|}{6.55} & \multicolumn{2}{|c|}{5.73} & \multicolumn{2}{|c|}{5.50} & - الإنحر اف المعيارى \\
\hline \multicolumn{2}{|c|}{22.24} & \multicolumn{2}{|c|}{22.55} & \multicolumn{2}{|c|}{23.00} & ــ المتوســـ الحسابى \\
\hline \multicolumn{2}{|c|}{56.2} & \multicolumn{2}{|c|}{57.5} & \multicolumn{2}{|c|}{59.2} & ـ ـ المتوســـط المرجح \\
\hline \multicolumn{2}{|c|}{3} & \multicolumn{2}{|c|}{2} & \multicolumn{2}{|c|}{1} & ـ الأهمية النسبية لرسمية العلاقة بين البحث و الإرشاد \\
\hline
\end{tabular}

وللتحقق من عدم وجود فروق معنوية بين بين آراء المبحوثين فى مدى رسمية العلاقة

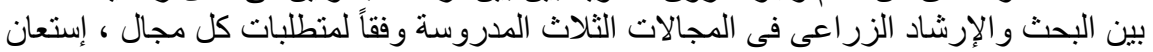

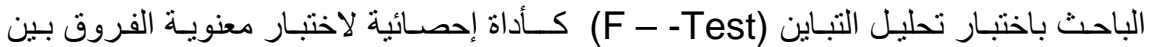

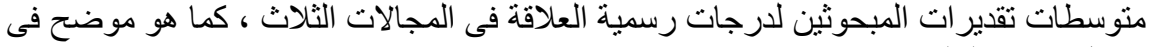
جدول ( 15 ) : تحليل التباين (f) بين تقديرات المبحوثين لارجة رسمية العلاقة بين البحث

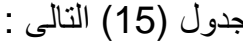
والارشاد الزراعى في المجالات الثثلاث المدروسية

\begin{tabular}{|c|c|c|c|c|c|c|}
\hline مستوية & قلمسمة فة & التباين & لدرجية & الانحر افات مربع & مصدرالاختلافات & شكل العلاقة \\
\hline 0.540 & 0.617 & $\begin{array}{c}122.640 \\
35.521\end{array}$ & $\begin{array}{c}2=\text { مقام=477 } 449 \\
449\end{array}$ & $\begin{array}{r}43.858 \\
15877.940 \\
15921.798\end{array}$ & ـ ـ ـ داخل المجموعات(450) & 2- رسمية العلاقة \\
\hline
\end{tabular}

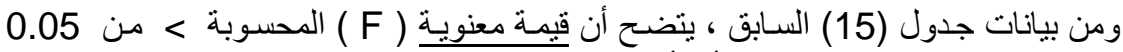

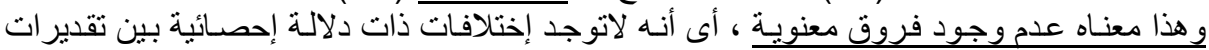

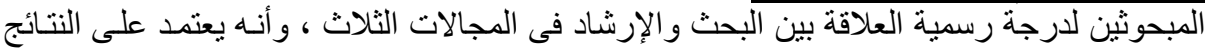

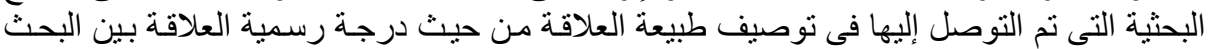

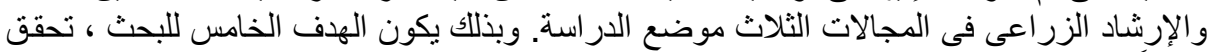
جزئياً. 


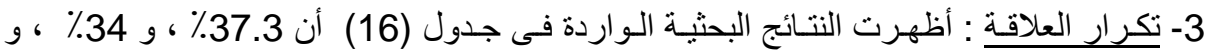

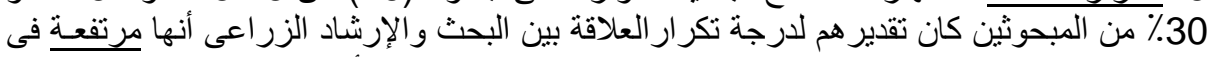

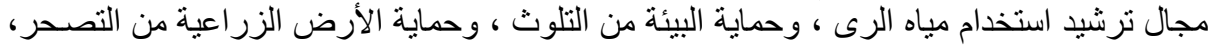

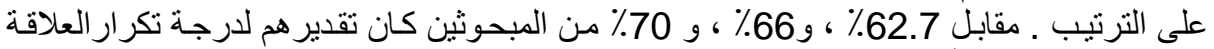

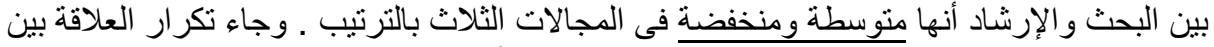

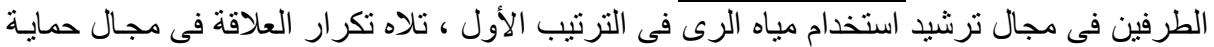

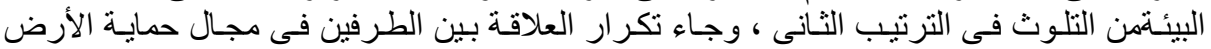

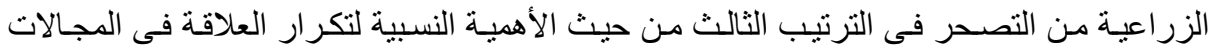
المدروسة. جدول ( 16 ) : توزيع المبحوثين وفقاً لتقديرهم لارجة تكرار العلاقة بين البحث والإرشاد

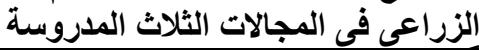

\begin{tabular}{|c|c|c|c|c|c|c|c|c|}
\hline \multicolumn{2}{|c|}{ الزأل الترضية من } & \multicolumn{2}{|c|}{ البيئة من حماية } & \multicolumn{2}{|c|}{ استخذام مياه الزي } & \multirow{2}{*}{\multicolumn{3}{|c|}{ درجة تكرار العلاقة }} \\
\hline$\%$ & العدد & $\%$ & العدد & $\%$ & التعدد & & & \\
\hline 23.3 & 35 & 19.3 & 29 & 16.7 & 25 & $(16$ & $-10)$ & - | | منذفضة \\
\hline 46.7 & 70 & 46.7 & 70 & 46.0 & 69 & (23 & $-17)$ & - مت متطظة \\
\hline 30.0 & 45 & 34.0 & 51 & 37.3 & 56 & $(30)(3)-1)(-1)$ & $-24)$ & 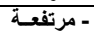 \\
\hline 100 & 150 & 100 & 150 & 100 & 150 & 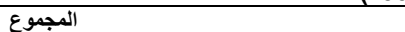 & & \\
\hline \multicolumn{2}{|c|}{6.22} & \multicolumn{2}{|c|}{5.07} & \multicolumn{2}{|c|}{5.59} & \multicolumn{3}{|l|}{ ـ الإنحر اف المعيارى } \\
\hline \multicolumn{2}{|c|}{20.84} & \multicolumn{2}{|c|}{21.4} & \multicolumn{2}{|c|}{21.52} & ـ المتوسأُ الحسابى & & \\
\hline \multicolumn{2}{|c|}{51.7} & \multicolumn{2}{|c|}{53.7} & \multicolumn{2}{|c|}{55.2} & ــ المتوســــ المرجح & & \\
\hline \multicolumn{2}{|c|}{3} & \multicolumn{2}{|c|}{2} & \multicolumn{2}{|c|}{1} & 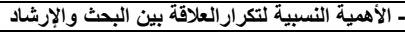 & & \\
\hline
\end{tabular}

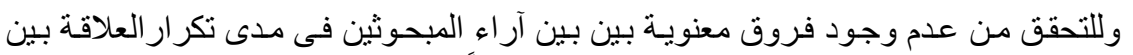

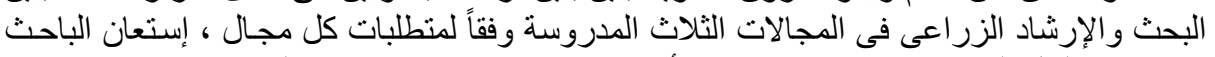

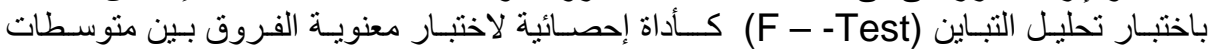

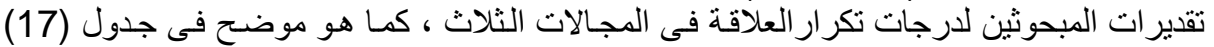
التالى :

جلول ( 17 ) : تعليل التباين (f) بين تقديرات المبحوثين لارجة تكرار العلاقة بين البحث

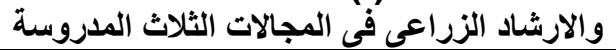

\begin{tabular}{|c|c|c|c|c|c|c|}
\hline المعنوية & قالمحسوبة & التباين & الحرية & الانحر افات مربع & مصدرالاختلافات & شكل العلاقة \\
\hline 0.556 & 0.57 & $\begin{array}{l}19.209 \\
33.675\end{array}$ & 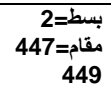 & $\begin{array}{r}38.418 \\
15052.693 \\
15091.111\end{array}$ & 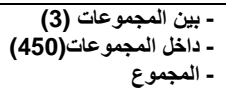 & 2- تكرار العلاقة \\
\hline
\end{tabular}

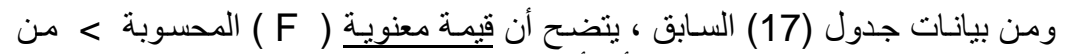

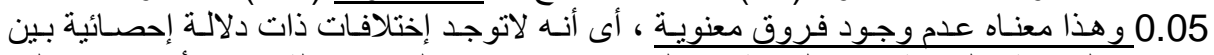

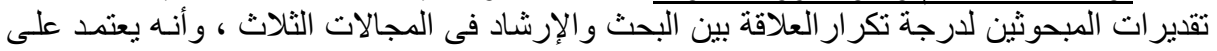

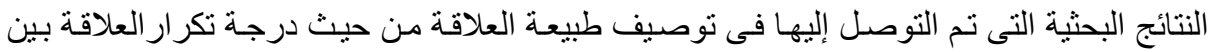

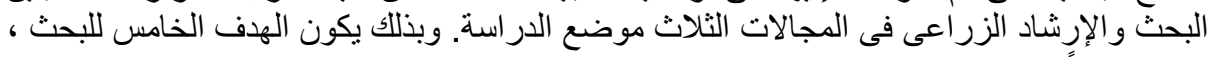
تحقق جزئياً.

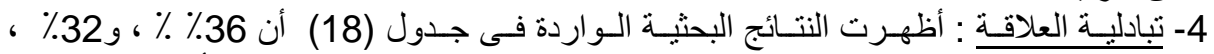

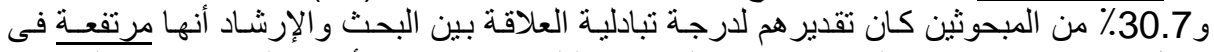

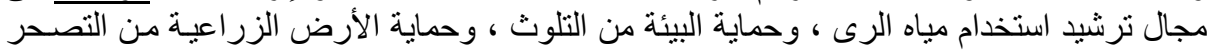




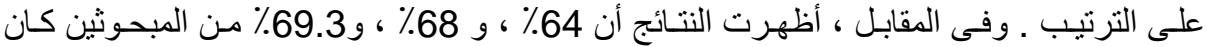

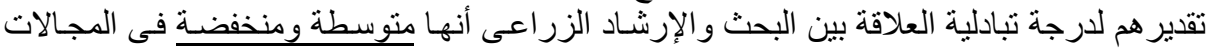

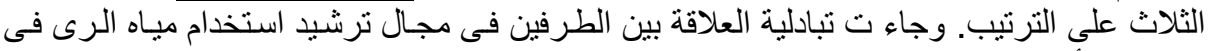

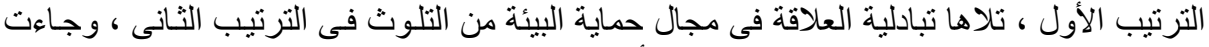

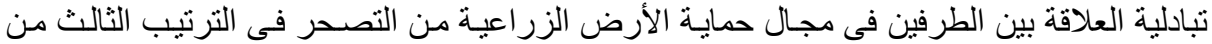

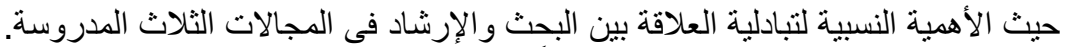

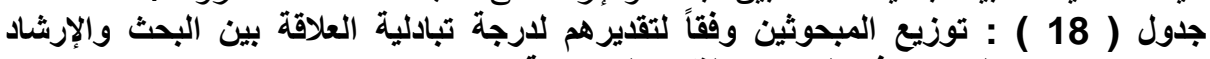

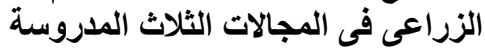

\begin{tabular}{|c|c|c|c|c|c|c|c|}
\hline \multicolumn{2}{|c|}{ الزرالية من التصحر الأرضر } & \multicolumn{2}{|c|}{ مجال حماية البيئة من } & \multicolumn{2}{|c|}{ مجال ترشيد استخدام مياه } & \multirow{2}{*}{\multicolumn{2}{|c|}{ درجة تبادلية العلاقة }} \\
\hline$\%$ & العدد & $\%$ & العدد & $\%$ & آلعدد & & \\
\hline 26.7 & 40 & 26.0 & 39 & 17.3 & 26 & $(16$ & ـ ـ منخفضـة ( 10 - \\
\hline 42.7 & 64 & 42.0 & 63 & 46.7 & 70 & (23 & - متوسـطة ( 17 - \\
\hline 30.7 & 46 & 32.0 & 48 & 36.0 & 54 & (30 & - مرتفعــة (24 - \\
\hline 100 & 150 & 100 & 150 & 100 & 150 & المجموع & \\
\hline \multicolumn{2}{|c|}{6.36} & \multicolumn{2}{|c|}{6.05} & \multicolumn{2}{|c|}{5.77} & - الإنحر اف المعيارى & \\
\hline \multicolumn{2}{|c|}{20.31} & \multicolumn{2}{|c|}{20.83} & \multicolumn{2}{|c|}{21.41} & - المتوســـ الحسابى & \\
\hline \multicolumn{2}{|c|}{51.0} & \multicolumn{2}{|c|}{51.5} & \multicolumn{2}{|c|}{54.7} & ـ ـ المتوســـ المرجح & \\
\hline \multicolumn{2}{|c|}{3} & \multicolumn{2}{|c|}{2} & \multicolumn{2}{|c|}{1} & 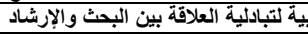 & - الأهمية النت \\
\hline
\end{tabular}

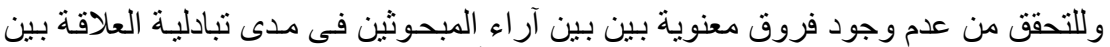

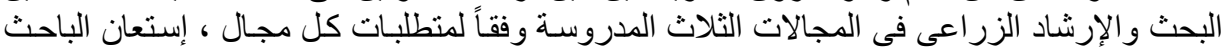

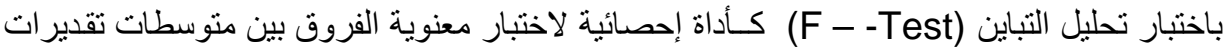

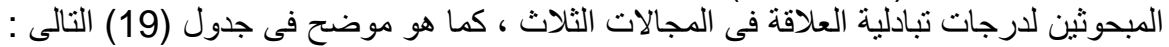

جدول ( 19 ) : تحليل التباين (f) بين تقديرات المبحوثين لارجة تبادلية العلاقة بين البحث

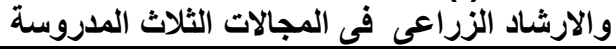

\begin{tabular}{|c|c|c|c|c|c|c|}
\hline المعنوية & قاليمة فية & التباين & الحرجية & مجموع مربع الاتحرافات & مصدرالاختلافات & شكل العلاقة \\
\hline 0.292 & 1.236 & $\begin{array}{l}45.442 \\
36.770\end{array}$ & 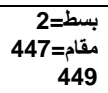 & $\begin{array}{r}90.880 \\
16436.140 \\
16527.024\end{array}$ & 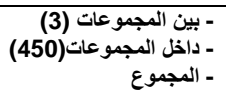 & 2- تبادلية العلاقة \\
\hline
\end{tabular}

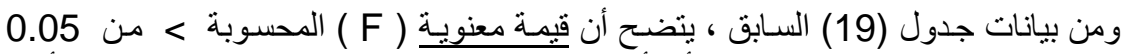

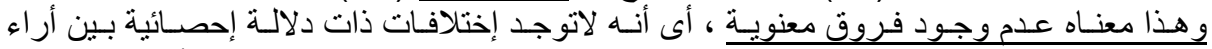

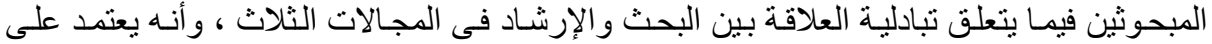

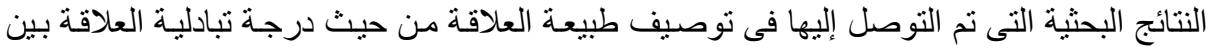

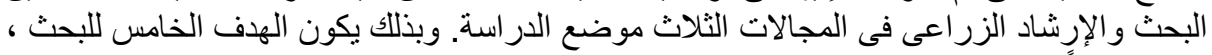
تحقق جزئياً .

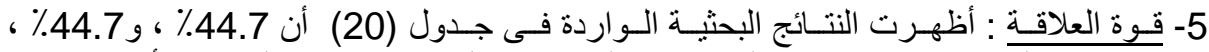

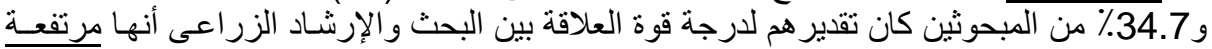

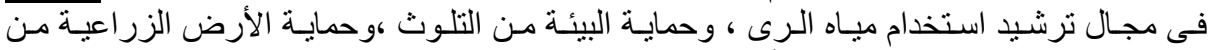

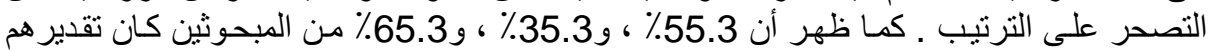

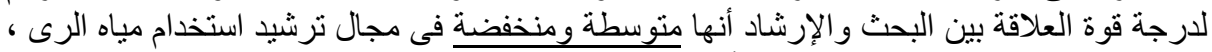

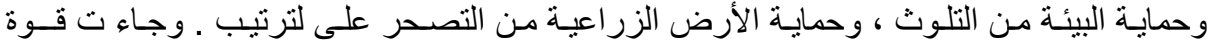

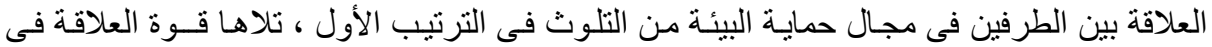




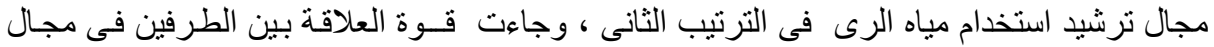

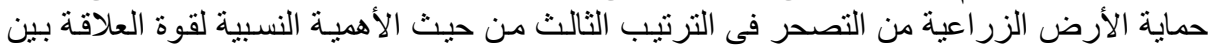

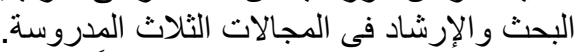
جدول ( 20 ) : توزيع المبحوثين وفقاً لتقديرهم لارجة الإنة قوة العلاقة بين البحث والإرشاد الزراعى

في المجالات الثلاث المدروسن

\begin{tabular}{|c|c|c|c|c|c|c|}
\hline \multicolumn{2}{|c|}{ الزراعية من التصحر الأرض } & \multicolumn{2}{|c|}{ مجال حماية البيئة } & \multicolumn{2}{|c|}{ مجال ترشيا استخدام } & \multirow{2}{*}{ درجة قوة العلاقة } \\
\hline$\%$ & العدد & $\%$ & العدد & $\%$ & العلدد & \\
\hline 24.7 & 37 & 16.0 & 24 & 18.0 & 27 & - منففضـة (10 - 10 - \\
\hline 40.7 & 61 & 39.3 & 59 & 37.3 & 56 & - متوسـطة ( 17 - 23 ( \\
\hline 34.7 & 52 & 44.7 & 67 & 44.7 & 67 & - مرتفعـــة ( 24 - 30 - \\
\hline 100 & 150 & 100 & 150 & 100 & 150 & 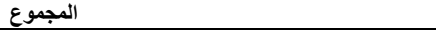 \\
\hline \multicolumn{2}{|c|}{6.55} & \multicolumn{2}{|c|}{6.23} & \multicolumn{2}{|c|}{6.22} & - الإنحراف المعيارى \\
\hline \multicolumn{2}{|c|}{20.92} & \multirow{2}{*}{\multicolumn{2}{|c|}{$\begin{array}{c}22.83 \\
57.2\end{array}$}} & \multicolumn{2}{|c|}{22.16} & ـ المتوســط الحسابى \\
\hline \multicolumn{2}{|c|}{52.5} & & & \multicolumn{2}{|c|}{56.7} & ــ المتوســـ المرجح \\
\hline \multicolumn{2}{|c|}{3} & \multicolumn{2}{|c|}{$\frac{57.2}{1}$} & \multicolumn{2}{|c|}{2} & ـ الأهمية النسبية لقوة العلاقة بين البحث والإرشاد \\
\hline
\end{tabular}

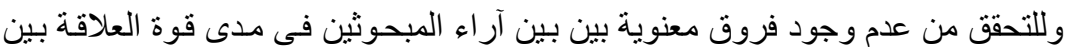

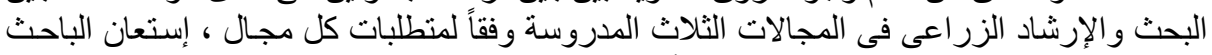

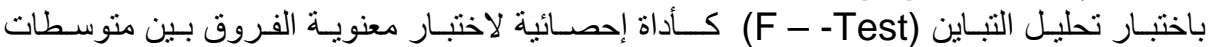
تقدير ات المبحوثين لدرجات قوة العلاقة فى المجالات الثلاث ، كما هو موضح فئ جدول منول (21) التالى

جدول ( 21 ) : تليل التباين (f) بين تقديرات المبحوثين لارجة قوة العلاقة بين البحث والارشاد

الزراعى في المجالات الثثلاث المدروسن المبرين

\begin{tabular}{|c|c|c|c|c|c|c|}
\hline المعنوية & قالمحسوبة في & التباين & الحرجية & مجموع مربع الانحرات & مصدر الاختلافات & شكل العلاقة \\
\hline 0.100 & 2.315 & $\begin{array}{l}92.940 \\
40.140\end{array}$ & $\begin{aligned} 2 & =\text { مقام:447 } \\
449 & \text { مبط }\end{aligned}$ & $\begin{array}{r}185.880 \\
17942.540 \\
18128.420\end{array}$ & ـ ـ ـ بين المجموعات (3) المجموع (450) & 2- قوة العلاقة \\
\hline
\end{tabular}

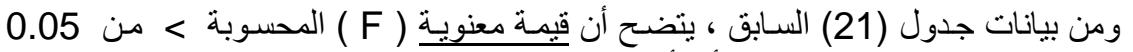

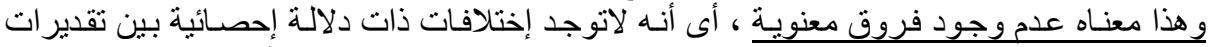

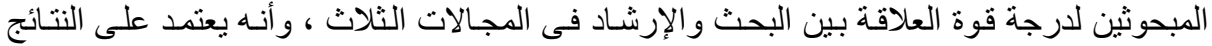

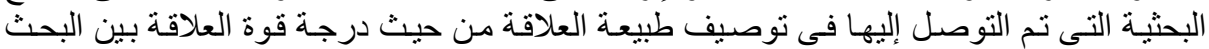

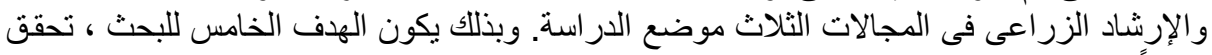
جزئياً.

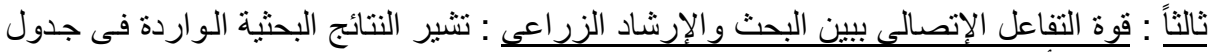

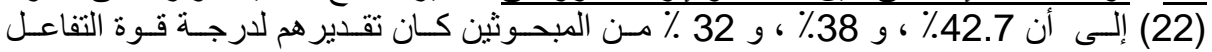

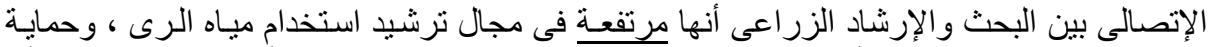

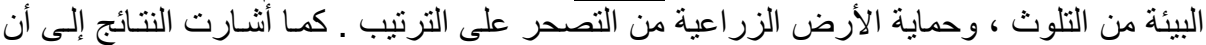

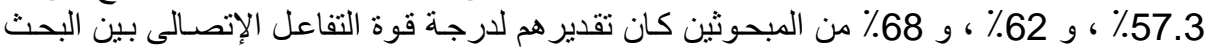

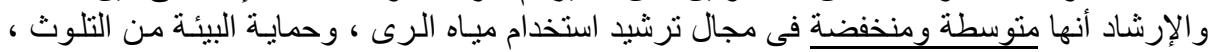

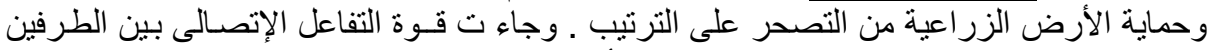

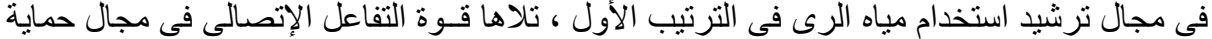

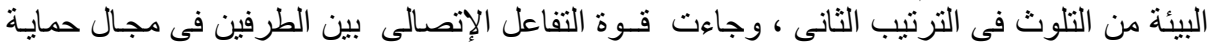


الأرض الزر اعية من التصحر فى الترتيب الثالث من حيث الأهمية النسبية لقوة التفاعل الاتصالى بين البحث و الإرشاد فى المجاعة من الات المدروسة . فئ.

جدول ( 22 ) : توزيع المبحوثين وفقاً لتقدير هم لارجة قوة التفاعل الإتصالى بين البحث والإرشاد الزراعى فى المجالات الثلاث المدروسة لتهنة

\begin{tabular}{|c|c|c|c|c|c|c|}
\hline \multicolumn{2}{|c|}{ مجال حماية الأرضر الزصر } & \multicolumn{2}{|c|}{ مجال حماية البيئة من } & \multicolumn{2}{|c|}{ مجال ترشيا استخدام مياه } & \multirow{2}{*}{ درجة قوة التفاعل الاتصالى } \\
\hline$\%$ & العدد & $\%$ & العدد & $\%$ & التعدد & \\
\hline 31.3 & 47 & 23.3 & 35 & 19.3 & 29 & - منففضـة ( 16 - 26 ( م) \\
\hline 36.7 & 55 & 38.7 & 58 & 38.0 & 57 & - متوسبطة ( 27 - 37 ) \\
\hline 32.0 & 48 & 38.0 & 57 & 42.7 & 64 & - مرتفعــة ( 38 - 48 - \\
\hline 100 & 150 & 100 & 150 & 100 & 150 & 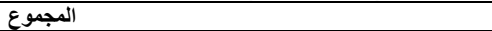 \\
\hline \multicolumn{2}{|c|}{10.7} & \multicolumn{2}{|c|}{10.0} & \multicolumn{2}{|c|}{9.85} & - - الإنحر اف المعيارى \\
\hline \multicolumn{2}{|c|}{31.7} & \multirow{2}{*}{\multicolumn{2}{|c|}{$\begin{array}{c}33.75 \\
53.7\end{array}$}} & \multicolumn{2}{|c|}{$\begin{array}{c}34.67 \\
55.8\end{array}$} & - المتوستــ الحسابي \\
\hline \multirow{2}{*}{\multicolumn{2}{|c|}{$\frac{50.2}{3}$}} & & & & & ـ ـ المتوســـ المرجح \\
\hline & & \multicolumn{2}{|c|}{2} & \multicolumn{2}{|c|}{1} & ـ الأهمية النسبيةلقوة التفاعل الاتصالى بين البحث والإرشاد \\
\hline
\end{tabular}

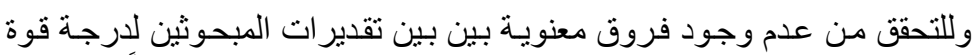

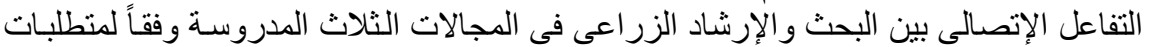

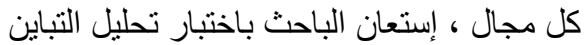

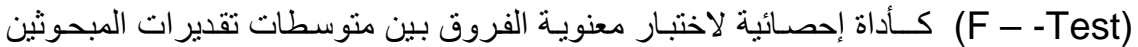

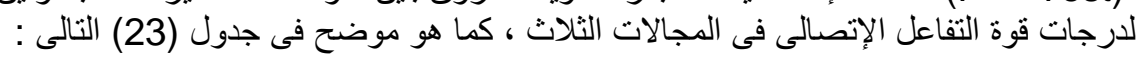

جدول ( 23 ) : : تحليل التباين (f) بين تقديرات المبحوثين لارجة قوة التفاعل الإتصالى بين

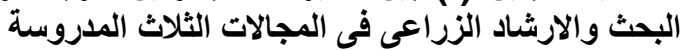

\begin{tabular}{|c|c|c|c|c|c|c|}
\hline المعنوية & قالمسمة فة & التباين & الرجرية & مجموع مربع & مصدرالاختلافات & شكل العلاقة \\
\hline 0.056 & 2.914 & $\begin{array}{l}302.409 \\
103.973\end{array}$ & $\begin{array}{rl}2 & =\text { بقام }=474 \\
447 & 449\end{array}$ & $\begin{array}{r}604.818 \\
46395.457 \\
47000.364\end{array}$ & 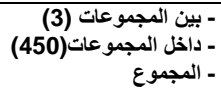 & التفاعل الاتصالى \\
\hline
\end{tabular}

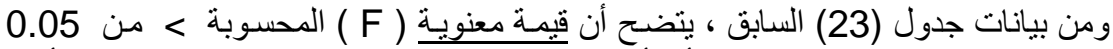

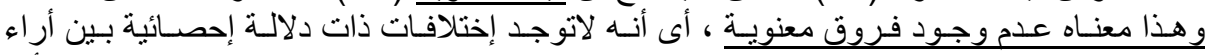

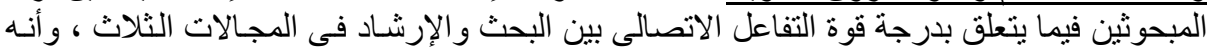

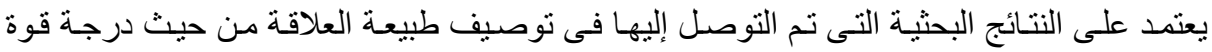

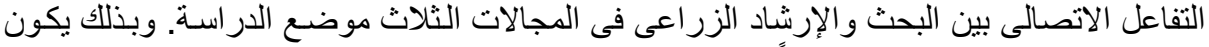
الهذف لخامس للبحث ، تحقق جزئياً.

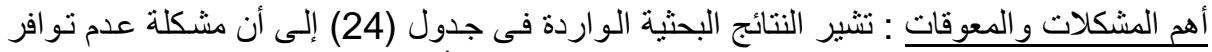

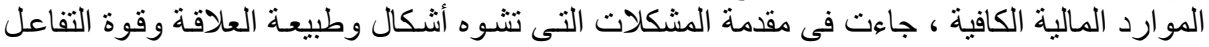

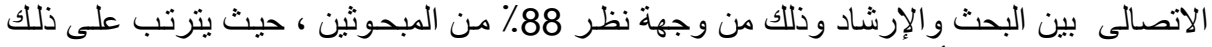
عدم كفاية البرامج و الأنشطة الإرشادية التنفيذية ، و وعدم كفاية طرق التهن التعليم الإرشادى . 
جدول (24): أهم المشكلات والمعوقات التى تثوه أشكال وطبيعة وقوة العلاقة بين البحث والإرشاد فى المجالات المدروسة من وجهة نظر المبات المبحوثين

\begin{tabular}{|c|c|c|c|c|c|c|c|}
\hline$\%$ & 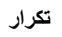 & المشكلاتو المعوقات & م & $\%$ & 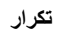 & المشكلاتو المعوقات & م \\
\hline 20.7 & 31 & ندرة البحوث التطبيقية فى هذه المجالات & 8 & 88.0 & 132 & عدم توافر الموارد المالية الكافية . & 1 \\
\hline 16.0 & 24 & تثجتالت الأفكار بين المتخصصين فى & 9 & 72.0 & 108 & الإنتاج إلزراكراعى ـ ـ التزوة التغير المناخى على & 2 \\
\hline 14 & 21 & عدم وجود قاعدة بيانات مشتركة . & 10 & 55.3 & 83 & عدم وجود تنسيق بين الطرفين. & 3 \\
\hline 12.7 & 19 & والإرشادية . ع عية فى البرامج البحثية & 11 & 38.0 & 57 & عدم وضوح السياسات البحثية والإرشادية. & 4 \\
\hline 12.0 & 18 & عدم وضوح المهام والإختصاصات . & 12 & 32.7 & 49 & غياب الحافز المادى للباحثين والأخصائيين. & 5 \\
\hline 11.3 & 17 & نقص الكوادرالإششادية . & 13 & 24.7 & 37 & والإشاد ـ . التظيط المشترك بين البحث & 6 \\
\hline 3.3 & 5 & الفساد الإدارى والمحسوبية . & 14 & 24.7 & 37 & عدم التعاون بين البحث والإرشاد الزراعى . & 7 \\
\hline
\end{tabular}

وجاءت مشكلة عدم إدر الك خطورة التغير المناخى على الإنتاج الزر اعى في في المرتبـة الثنانية

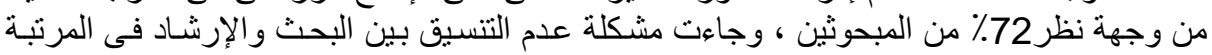

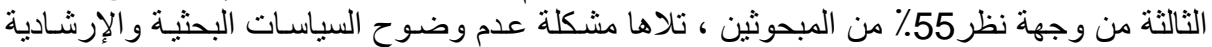

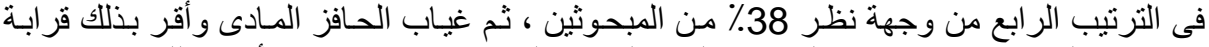

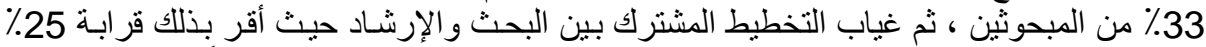

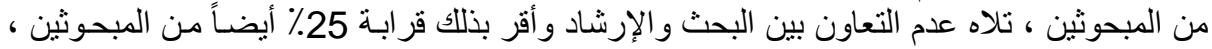

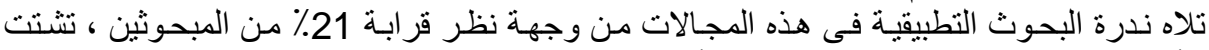

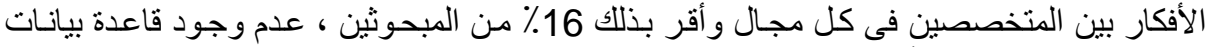

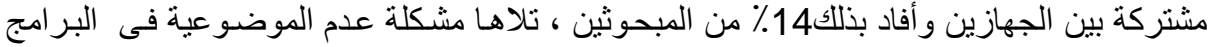

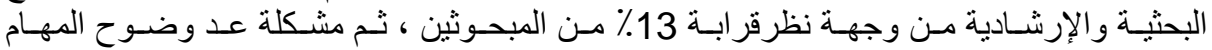

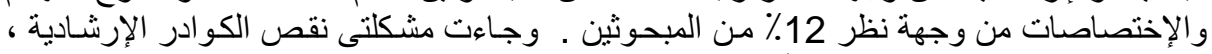

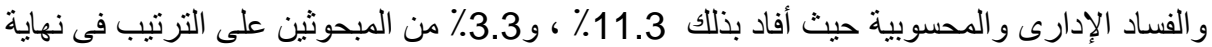

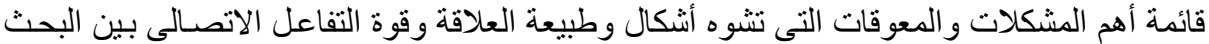

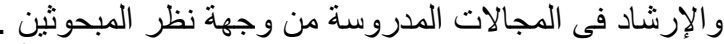
التوصيات البحثية

فى ضو ء ما أسفر عنه البحث من نتائج ومضامين بحثية ، فإنه يمكن التوصية بما يلى :

1- توفير الدعم المادى للبحث الزراعى والإرشاد الزر اعى للإنفاق منها على منطلبات تنفيذ الأنشطة البحثية و الإرشادية . 2- وضع برامج و اضحة الإرية الأهداف فى مجالات نرشيد استخدام مياه الرى ، وحماية البيئة من التلوث ، وحمايةالأرض برض

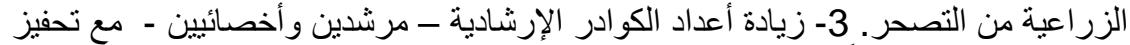

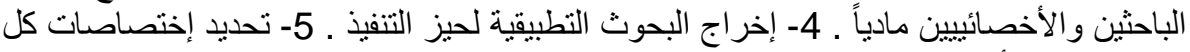

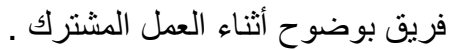
6- تكثيف الدور ات التدريية للفريقين فى مجال تغير المناخ. 7- ضرورة القيام بالتخطيط و التنسيق المشترك ت 


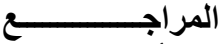

أبو الخير ، كمال حمدى ( دكتور ) ، ( 1974) (1974): أصول الإدارة العلمية ، مكتبة عين شمس.

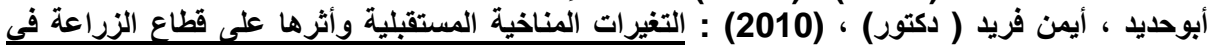

مصر وكيفية فرية

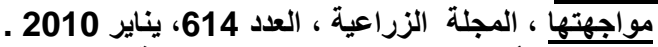

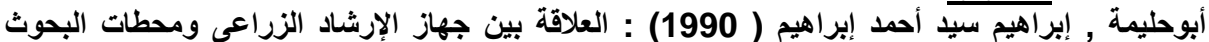

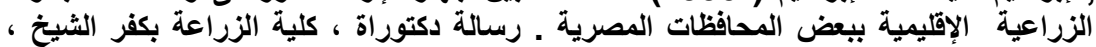

جامعة طنطا.

بهاء الدين ، شيماء ( 2014) : مواجهة تأثيرات التغيرات المناخية على الزراعة المصرية ،

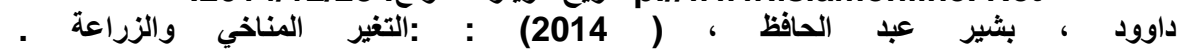

http://www.zira3a.net/articles/climate-

2014/11/18 تاريخ الزيارة: change.html

زيدان ، عماد أنور، ( 2000) : الاحتياجات التدريبية للمرشدين الزراعيين في مجال أساليب ترشيل استخدام

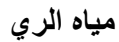

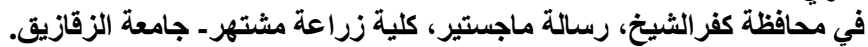

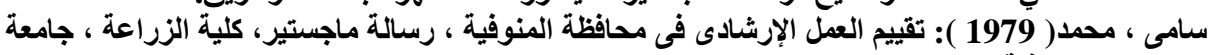
المنوفية.

سويف ، مصطفى ( دكتور ) ، ( 1960): الأسس النفسية للتكامل الإجتماعى دراسة إرتقائية تحليلية ،

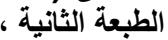

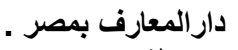

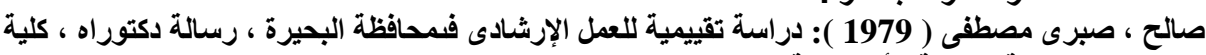
الزراعة، جامعة الأسكندرية.

عبد الرحمن ،على (دكتور) ، ( 2014) : الابعناد الاقتصادية لظاهرة التصحر فى جمهورية مصر العربية

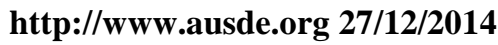

عبد الفتاح ، محمد سعيد ( دكتور ) ، (1971) ) : الإدارة العامة ، المكتب المصرى الحديث ، القاهرة .

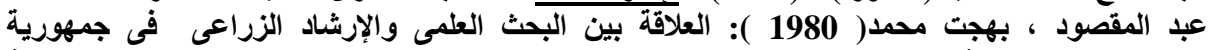

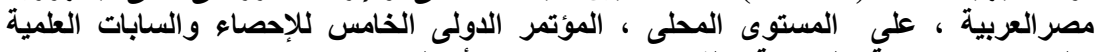

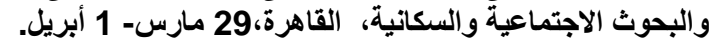

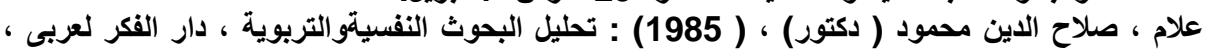
القاهرة.

فاوي ، سحر ( 2009) ، عرض دراسة تناقش الآثار الاقتصادية والبيئة للزراعة العضوية، المجلة

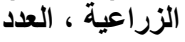

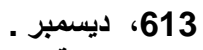

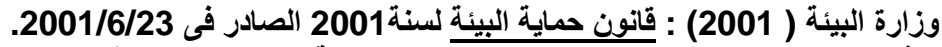

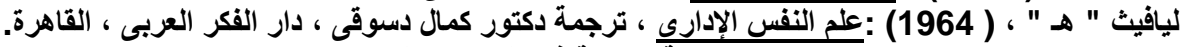

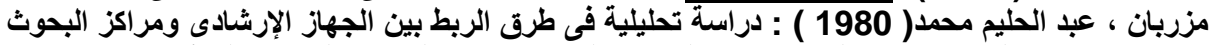

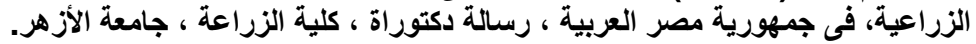




\title{
A STUDY OF THE FORMS OF THE RELATIONSHIP BETWEEN RESEARCH AND EXTENSION IN SOME FIELDS OF REDUCING THE IMPACT OF CLIMATE CHANGES ON THE AGRICULTURAL PRODUCTION IN ELBEHERAH AND KAFRELSHEIKH GOVERNORATE
}

\author{
Zakaria Mohamad Alzarka*, Mahmoud Ismaiel Etman**, \\ Amal Abd-Elrasul Fayedªnd Hamdy Abdel-Rhman Al- \\ Deeb** $^{\star *}$ \\ ${ }^{*}$ Faculty of Agriculture - Damanhur \\ Agricultural Research \\ Center \\ Faculty of Agriculture - Damanhur \\ ${ }^{\star *}$ Agricultural Research Center
}

\begin{abstract}
This research aims mainly to study the forms of the relationship between research and extension in some areas of reducing the impact of climate changes on the agricultural production in Elbeherah and Kafrelsheikh governorates. The research had two populations are: 1- The agricultural extension specialists in both governorates, 2- The agricultural researchers in the research stations in both governorates.

It was selected simple random sample amounted to 150 respondents, represented 34\% from each population. Data were collected using a questionnaire by personal interview with the respondents during September and October 2015.Frequency, percentage, arithmetic mean, stander deviation, weighted mean, and both of $T \& F$ tests, to analysis data statistically.
\end{abstract}

The main results were as follows:

First: Forms of relationship:

" $68 \%, 26.7 \%$, and $62 \%$ of the respondents, their estimation degree of cooperation between research

and Agricultural. extension were medium and low in the field of rationalization of the irrigation

water use, protection of the environment from pollution, and protection of agricultural land from

desertification, respectively.

» $61.3 \%, 70 \%$, and $73.4 \%$ of the respondents, their estimation degree of coordination between

research and Agricultural extension were medium and low in the field of rationalization of the

irrigation water use, protection of the environment from pollution, and protection of agricultural

land from desertification, respectively. 
" $67.3 \%, 64 \%$, and $78 \%$ of the respondents their estimation degree of integration between research

and Agricultural extension were medium and low in the field of rationalization of the irrigation

water use, protection of the environment from pollution, and protection of agricultural land from desertification, respectively.

» $89.3 \%, 90.6 \%$ and $87.3 \%$ of the respondents their estimation degree of conflict between research and

Agricultural extension were medium and low in the field of rationalization of the irrigation water

use, protection of the environment from pollution, and protection of agricultural land from

desertification, respectively.

》 $28.7 \%, 28.7 \%$, and $32 \%$ of the respondents their estimation degree solutions finding between

research and Agricultural extension were medium and low in the field of rationalization of the

irrigation water use, protection of the environment from pollution, and protection of agricultural

land from desertification, respectively.

Second: Nature of relationship:

» $27.3 \%$, $28.7 \%$, and $30.7 \%$ of the respondents their estimation degree of importance of the relationship

between research and Agricultural extension were medium and low in the field of rationalization of

the irrigation water use, protection of the environment from pollution, and protection of agricultural

land from desertification, respectively.

》52\%,57.4\%, and $56.7 \%$ of the respondents ,their estimation degree of the formality of relationship

between research and Agricultural extension were medium and low in the field of rationalization of

the irrigation water use, protection of the environment from pollution and protection of agricultural

land from desertification, respectively.

》 $62 \%, 66 \%$, and $70 \%$ of the respondents their estimation degree frequency of relationship between

research and Agricultural extension were medium and low in the field of rationalization of the

irrigation water use, protection of the environment from pollution, and protection of agricultural

land from desertification, respectively.

》 $64 \%, 68 \%$, and $69 \%$ of the respondents their estimation degree of reciprocal relationship between

research and Agricultural extension were medium and low in the field of rationalization of the 
irrigation water use, protection of the environment from pollution, and protection of agricultural land from desertification, respectively.

» $55.3 \%, 33.3 \%$, and $55.4 \%$ of the respondents ,their estimation degree of strength of the relationship

between research and Agricultural extension were medium and low in the field of rationalization of

the irrigation water use, protection of the environment from pollution and protection of agricultural

land from desertification, respectively.

Third: Strength of Communication Interaction:

» $57.3 \%, 62 \%$, and $67 \%$ of respondents their estimation degree of the interaction of the relationship between research and Agricultural extension were medium and low in the field of rationalization of

the irrigation water use, protection of the environment from pollution, and protection of agricultural

land from desertification, respectively.

Fourth: The most important problems and obstacles that distort the forms, nature, and strength

of the interaction between research and extension in the studied fields from the respondents point of

view of were: Lack of adequate financial resources, lack of awareness of the seriousness of climate

change on agricultural production, the lack of coordination between the parties, lack of clarity in

research and extension policies, and the lack of financial incentive for researchers and

specialists. 